\title{
Synthesis and parameter optimization of a combined sugar and ethanol production process integrated with a CHP system
}

\author{
Matteo Morandin ${ }^{a}$, Andrea Toffolo ${ }^{a}$, Andrea Lazzaretto ${ }^{a}$, , François Maréchal ${ }^{b}$, Adriano V. Ensinas ${ }^{c}$, \\ Silvia A. Nebra ${ }^{\mathrm{d}}$ \\ a Department of Mechanical Engineering, University of Padova, via Venezia 1, 35131, Padova, Italy \\ ${ }^{\mathrm{b}}$ LENI Industrial Energy Systems Laboratory, EPFL, Bat. ME A2 Station 9 CH-1015 Lausanne, Switzerland \\ ${ }^{\mathrm{C}}$ CECS, Federal University of ABC (UFABC), Av. dos Estados 5001, Santo André, Brazil \\ ${ }^{\mathrm{d}}$ NIPE Interdisciplinary Centre for Energy Planning, University of Campinas, Cid. Universitaria Zeferino Vaz, P.O. Box 1170, Campinas, Brazil
}

\section{A R T I C L E I N F O}

\section{Article history:}

Received 2 March 2010

Received in revised form

21 October 2010

Accepted 27 October 2010

Available online 8 December 2010

\section{Keywords:}

Process integration

Sugar-cane

Ethanol

Pinch analysis

Biomass

\begin{abstract}
A B S T R A C T
The combined sugar and ethanol production process from sugar cane is a paradigmatic application for energy integration strategies because of the high number of hot and cold streams involved, the external hot utility requirement at two temperature levels for juice evaporation and crystallization, and the electricity demand for juice extraction by milling. These conditions make it convenient to combine the sugar-cane process with a CHP system fuelled by bagasse, the main by-product from juice extraction. The strategies, tools and expertise on energy integration developed separately by the research teams authoring this paper are applied here jointly to optimize the synthesis and the design parameters of the process and of the total site starting from the basic idea of dissociating the heat exchanger network design problem from the total site synthesis problem. At first the minimization of the external heat requirement for the process alone is pursued and results show that a one third reduction can be achieved by optimal heat integration. Then the use of the by-product bagasse for on-site power generation is considered and two bagasse-fuelled CHP systems are optimized along with some parts of the sugar and ethanol production process in order to obtain maximum total site net power. Results show a variety of interesting scenarios of combined sugar, ethanol and electricity production plants with considerably high electricity output.
\end{abstract}

(c) 2010 Elsevier Ltd. All rights reserved.

\section{Introduction}

The advantages of applying energy integration techniques to improve the efficiency of energy intensive plants have already been discussed by several authors in the literature. Chemical processes are a typical field of application because a high number of material and energy streams are usually involved at different temperature levels. This feature allows the designer to consider a series of process modification options that realize a good energy integration, the ultimate aim remaining the best trade-off between operating costs and plant complexity.

Margins for improvement are defined by the degrees of freedom of the designer. These concern the selection of the process units to realize the chemical conversion, overall plant configuration and design parameters such as temperatures, pressures and mass flow rates. The system has to be considered as a whole in order to fully

\footnotetext{
* Corresponding author. Tel.: +39 049827 6747; fax: + 390498276785 .

E-mail address: andrea.lazzaretto@unipd.it (A. Lazzaretto).
}

exploit the opportunities offered by process integration and combined heat and power production (CHP) options such as fossil fuelled steam or gas turbine plants. The number of degrees of freedom further increases when renewable energy resources are considered. For example, biomass can be used as fuel and burnt directly, gasified or co-transformed into biofuel.

Several techniques were developed in the literature to deal with energy integration problems (among others, Pinch analysis [1], exergy and thermoeconomic analyses [2], expert systems [3]). LENI developed a software, named EASY, to deal with the general "synthesis problem" in complex energy systems. EASY finds the best heat integration among system thermal streams by solving a mixed-integer linear programming problem, subject to the linear inequality constraints of heat transfer feasibility, in which the binary variables are associated with different parts of system superstructure and the continuous variables are the mass flow rates in such parts. LENI also suggested to apply this method to all the possible values of system design parameters. Accordingly, the optimal boundary conditions of the overall heat transfer section within 
the system (i.e. including all thermal streams existing in the optimal system configuration) are found using the so-called Effect Modeling and Optimization method [4]. In the different perspective of total system synthesis and design optimization, the so-called HEATSEP method $[5,6]$ suggests to virtually separate the heat transfer section from the rest of the system (the "basic" plant configuration), and to leave its configuration completely undefined. This separation is achieved by "cutting" all the possible thermal links between components (i.e. the temperature at the inlet of a component is free to vary independently of the temperature at the outlet of the preceding component) and generates the set of all the potential thermal streams of the system. The search for the optimal "basic" plant configuration and the optimal values of its design parameters (including all the temperatures made free by thermal link cuts) is then performed by an optimizer that, therefore, determines the optimal boundary conditions of the overall heat transfer section within the system, as the LENI approach does.

Starting from this background, the authors decided to share their expertise in this paper in order to investigate the potential ways for energy integration improvement in a sugar-cane conversion process, first focusing on the process only and then including a CHP system fuelled with the main process by-product (bagasse). The case has been widely studied in the literature (see, e.g.,[7-12]), as it is complex and paradigmatic. This work follows a work on the same subject $[13,14]$, in which the model of an existing sugar-cane plant for combined sugar and ethanol production is presented in detail along with possible design improvements.

The base case sugar-cane conversion process is first analyzed in Section 3 in order to obtain reference values for the heat streams involved and for the energy requirements of the process. The operating parameters and the configuration of the base case scenario are taken from [14]. The ratio between sugar and ethanol production rates is then considered as a parameter in the analysis. In addition to the value used in the base case process configuration (31\% sugar and 69\% ethanol by mass), other two production ratios are considered (50\% sugar, 50\% ethanol and 67\% sugar and $33 \%$ ethanol). Different energy and heat loads in the sugar-cane conversion process are obtained by varying this ratio, since the juice mass flow rates in some components change.

The optimization problems tackled in Section 4 and Section 5 deal with a process in which the raw material (sugar-cane) is fixed and all the mechanical and chemical transformations of both this material and its sub-products (juice, bagasse, molasses) are fixed to design point conditions. In Section 4 the sugar-cane conversion process into sugar and ethanol is considered alone, and the synthesis and design variables of the multi-effect evaporator are optimized to achieve the minimum process thermal requirement. In Section 5 two bagasse fuelled CHP systems are coupled to the sugar-cane conversion process, a traditional steam cycle (based on a condensing turbine with one steam extraction) and an integrated gasification combined cycle. Some design parameters of the two CHP systems are optimized together with some synthesis and design parameters of the sugar-cane conversion process in order to produce the maximum net electricity to be sold to the market by using the whole amount of bagasse extracted from the input sugar-cane stream.

In both kind of problems the system is optimized according to purely thermodynamic objectives. Moreover, the problem of defining the heat exchanger network that accomplishes the optimal heat integration is left to be solved by a subsequent synthesis problem and is not presented here. In fact, the most profitable total site heat exchanger network configuration can be found only by performing a thermoeconomic analysis, which is beyond the scope of the present paper. Nevertheless, the results presented here are useful to understand the maximum potential for energy savings in the sugar-cane conversion process and maximum potential for on-site electricity production when considering a bagasse fuelled CHP system.

\section{The sugar-cane conversion into sugar and ethanol: plant overview}

A concise description of the sugar-cane conversion plant for sugar and ethanol production is given in this section. More detailed information about this industrial process may be found in the books by Hugot [15] and Rein [16]. The reader is also referred to [17] and [18] for the sugar and ethanol production processes, respectively.

\subsection{Sugar-cane}

Sugar-cane basically consists of water (mass fraction $73-76 \%$ ), soluble solids (10-16\%) and dry fiber (11-16\%). Soluble solids are the chemical compounds that must be extracted from raw biomass and then converted into the desired products. In particular, the main compound involved in sugar and ethanol production is sucrose, which is the major component of soluble solids (up to $88 \%$ of the soluble solid mass fraction), while the remaining part is made of glucose, fructose, salts and other organic compounds [17]. The conversion of the sugar-cane into the two desired products consists in a sequence of physical and chemical operations which occur in seven basic subsystems (Fig. 1).

\subsection{Juice extraction and treatment}

The sugar-cane is first chopped by knives and then smashed in a set of mills in which water is added in order to dissolve the soluble solids and extract them from the original fibrous structure of the cane. These operations are carried out in the extraction subsystem (subsystem 1). At this point, the juice stream is split into two parts,

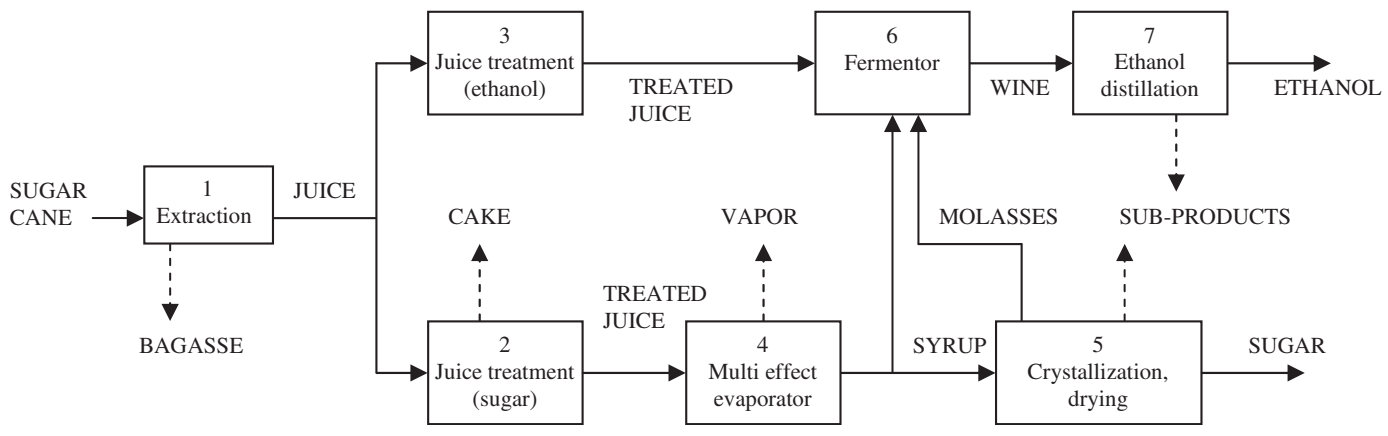

Fig. 1. Schematic representation of the sugar-cane process. 
one used for the ethanol production chain and the other for the sugar production chain. Actually, as it will be shown in the following sections, a number of streams departing from the sugar production subsystems are diverted to the ethanol production subsystems in order to obtain the desired solid and sucrose concentrations for the conversion of sucrose into ethanol.

At the outlet of the extraction, juice with high water content and a $10-15 \%$ mass fraction of solids is obtained and then sent to the juice treatment section. The juice extracted from biomass, in fact, still has a quite high content of undesired organic compounds and has to be purified. In this process, the undesired "sugar inversion" reaction (i.e. the hydrolysis of sweeter sucrose into fructose and glucose) may occur and so, in order to inhibit it, the juice is heated up almost to the boiling point at $115^{\circ} \mathrm{C}$ and then is properly treated with chemicals (lime and sulfuric acid) in a clarifier. As a consequence, some inorganic material precipates and is eventually conveyed to a filter and washed. The filter cake is discarded and part of the water is recycled upstream the clarifier. Since Sulphur is not desired for ethanol production, the juice for sugar and ethanol production is treated in two different subsystems ( 2 and 3 ).

\subsection{Juice evaporation and sugar crystallization}

Sugar production mainly consists in sucrose extraction and crystallization. The juice coming from the clarification process, which has usually a low sucrose content (around 10-16\%, "thin" juice), is concentrated in the evaporator in a multi-effect evaporator (subsystem 4) up to the saturation concentration (sucrose mass fraction equal to 62-69\%, "thick" juice). If multiple shell evaporators were used, an independent hot stream would be required for each shell and, in addition, the vapor phase of each evaporation unit (basically made of water and low-boiling substances from the juice) would be simply extracted, condensed and sent to the sewage treatment. Multi-effect evaporators are typically employed in food and pulp-and-paper industry, where the evaporation of the water of the raw material is an energy intensive procedure. Evaporator units (or effects) are usually of the Robert calandria type. In the first effect the juice is heated by a steam flow, which then condenses and exits from the bottom of the evaporator (this results in a stream of pure condensed water to be recycled to the steam boiler). On the juice side, the vapor phase exits the unit on the top and is used as a heat source for the second effect, following the design principle of a cascade of evaporation effects. In the case of co-current multi-effect evaporator, the juice is evaporated at progressively lower pressure levels which correspond to lower steam saturation temperatures as well. In so doing the heat of the vapor phase from an upstream evaporation unit can be exploited as a heating source for the downstream unit. Usually, the last effect operates at $0.1-0.2$ bar, while the temperature of the liquor decreases from $130{ }^{\circ} \mathrm{C}$ (first effect) to $90{ }^{\circ} \mathrm{C}$ (last effect) [17].

The juice is then crystallized (subsystem 5) by evaporating crystallization, cooling crystallization and centrifugation. The byproduct of these processes are the molasses ( by mass, sugar mass fraction $=50-60 \%$, non-sugar mass fraction $=32-40 \%$ ), which are recycled to the syrup mixer just before the fermentation stage. The thick juice is heated in pans up to the evaporation temperature at $0.2-0.3$ bar $\left(65-80{ }^{\circ} \mathrm{C}\right)$ till metastable crystallization conditions are reached. Crystallization is promoted by seeding some microcrystals, and is prolonged until crystals grow to the desired size. At the end of the process, centrifuges are used to separate the crystallized sugar from the molasses. Up to $85 \%$ of the white sugar is produced by evaporating crystallization and centrifugation processes. The remaining syrup can still be used for the production of additional white sugar by means of cooling crystallization, in which sugar solubility in water is lowered by reducing the temperature of the solution from 65 to $35^{\circ} \mathrm{C}$. Finally, surface water content must be reduced up to $0.03-0.05 \%$ with an airdrier [17].

\subsection{Fermentation and ethanol distillation}

Ethanol is produced by yeast fermentation of sucrose (subsystem 6). In the fermenting process the sucrose in the syrup undergoes the biochemical transformations that convert sugar into ethanol, $\mathrm{CO}_{2}$ and other organic substances and alcohols. The reaction is exothermic and needs cooling to maintain fermenting conditions. Yeasts are added to the substrate along with some nutrients (minerals) that are useful for yeast growth. The optimal concentration of sucrose depends on process type and is typically between 10 and $20 \%$ by mass in water. Ethanol inhibits yeast growth so the content of produced ethanol has to be lower than $15-20 \%$ by volume in the fermentor. The optimal fermentation

Table 1

Base case data for the sugar-cane process.

\begin{tabular}{|c|c|c|}
\hline Subsystem & Inputs & Outputs \\
\hline 1- Extraction & $\begin{array}{l}\text { Sugar cane }(138.9 \mathrm{~kg} / \mathrm{s}) \\
\text { Washing water }(740.3 \mathrm{~kg} / \mathrm{s}) \\
\text { Imbibition water }(41.7 \mathrm{~kg} / \mathrm{s}) \\
\text { Electricity }(1250 \mathrm{~kW}) \\
\text { Mechanical power for mills } \\
(8000 \mathrm{~kW})\end{array}$ & $\begin{array}{l}\text { Raw juice at } 35^{\circ} \mathrm{C} \\
(141.7 \mathrm{~kg} / \mathrm{s}) \\
\text { Bagasse }(38.9 \mathrm{~kg} / \mathrm{s})\end{array}$ \\
\hline $\begin{array}{l}2 \text { - Juice treatment } \\
\text { (sugar) }\end{array}$ & $\begin{array}{l}\text { Juice }(98.82 \mathrm{~kg} / \mathrm{s})^{\mathrm{a}} \\
\text { Lime }(0.11 \mathrm{~kg} / \mathrm{s}) \\
\text { Sulphur }(0.06 \mathrm{~kg} / \mathrm{s}) \\
\text { Water lime }(2.24 \mathrm{~kg} / \mathrm{s}) \\
\text { Bagacillo }(0.48 \mathrm{~kg} / \mathrm{s}) \\
\text { Filter water }(6.78 \mathrm{~kg} / \mathrm{s}) \\
\text { Electricity }(701 \mathrm{~kW})\end{array}$ & $\begin{array}{l}\text { Treated juice at } 97{ }^{\circ} \mathrm{C} \\
(103.5 \mathrm{~kg} / \mathrm{s}) \\
\text { Vapor at } 97{ }^{\circ} \mathrm{C}(1.44 \mathrm{~kg} / \mathrm{s}) \\
\text { Vapor at } 73{ }^{\circ} \mathrm{C}(0.21 \mathrm{~kg} / \mathrm{s}) \\
\text { Cake }(3.39 \mathrm{~kg} / \mathrm{s})\end{array}$ \\
\hline $\begin{array}{l}\text { 3- Juice treatment } \\
\text { (ethanol) }\end{array}$ & $\begin{array}{l}\text { Juice }(42.86 \mathrm{~kg} / \mathrm{s})^{\mathrm{a}} \\
\text { Lime }(0.05 \mathrm{~kg} / \mathrm{s}) \\
\text { Bagacillo }(0.21 \mathrm{~kg} / \mathrm{s}) \\
\text { Filter water }(2.94 \mathrm{~kg} / \mathrm{s}) \\
\text { Water lime }(0.97 \mathrm{~kg} / \mathrm{s}) \\
\text { Electricity }(304 \mathrm{~kg} / \mathrm{s})\end{array}$ & $\begin{array}{l}\text { Treated juice at } 97{ }^{\circ} \mathrm{C} \\
(44.84 \mathrm{~kg} / \mathrm{s}) \\
\text { Vapor at } 97{ }^{\circ} \mathrm{C}(0.63 \mathrm{~kg} / \mathrm{s}) \\
\text { Vapor at } 73{ }^{\circ} \mathrm{C}(0.09 \mathrm{~kg} / \mathrm{s}) \\
\text { Cake }(1.47 \mathrm{~kg} / \mathrm{s})\end{array}$ \\
\hline $\begin{array}{l}4 \text { - Multi-effect } \\
\text { evap. }\end{array}$ & $\begin{array}{l}\text { Juice }(103.4 \mathrm{~kg} / \mathrm{s}) \\
\text { Electricity }(849 \mathrm{~kW})\end{array}$ & $\begin{array}{l}\text { Vapor } 1 \mathrm{st} \text { effect } \\
(42.34 \mathrm{~kg} / \mathrm{s}) \\
\text { Vapor } 2 \mathrm{nd} \text { effect } \\
(8.50 \mathrm{~kg} / \mathrm{s}) \\
\text { Vapor } 3 \mathrm{rd} \text { effect } \\
(9.25 \mathrm{~kg} / \mathrm{s}) \\
\text { Vapor } 4 \text { th effect } \\
(9.62 \mathrm{~kg} / \mathrm{s}) \\
\text { Vapor } 5 \text { th effect } \\
(10.67 \mathrm{~kg} / \mathrm{s}) \\
\text { Syrup at Brix } 65 \\
(22.97 \mathrm{~kg} / \mathrm{s})\end{array}$ \\
\hline $\begin{array}{l}5 \text { - Boiling, } \\
\text { centrifuges } \\
\text { and drying }\end{array}$ & $\begin{array}{l}\text { Syrup }(21.08 \mathrm{~kg} / \mathrm{s})^{\mathrm{b}} \\
\text { Electricity }(3321 \mathrm{~kW}) \\
\text { Water }(3.48 \mathrm{~kg} / \mathrm{s})\end{array}$ & $\begin{array}{l}\text { Molasses }(5.83 \mathrm{~kg} / \mathrm{s}) \\
\text { White sugar }(9.21 \mathrm{~kg} / \mathrm{s}) \\
\text { Other sub-products } \\
(2.56 \mathrm{~kg} / \mathrm{s})\end{array}$ \\
\hline 6 - Fermentor & $\begin{array}{l}\text { Treated juice }(44.84 \mathrm{~kg} / \mathrm{s}) \\
\text { Syrup }(1.84 \mathrm{~kg} / \mathrm{s})^{\mathrm{b}} \\
\text { Molasses }(5.83 \mathrm{~kg} / \mathrm{s}) \\
\text { Other chemicals and water } \\
(13.18 \mathrm{~kg} / \mathrm{s}) \\
\text { Electricity }(352 \mathrm{~kW})\end{array}$ & $\begin{array}{l}\text { Wine at } 6.8 \text { \%ethanol } \\
(61.68 \mathrm{~kg} / \mathrm{s}) \\
\mathrm{CO}_{2}(4.01 \mathrm{~kg} / \mathrm{s})\end{array}$ \\
\hline $\begin{array}{l}7 \text { - Ethanol } \\
\text { distillation }\end{array}$ & $\begin{array}{l}\text { Wine }(61.68 \mathrm{~kg} / \mathrm{s}) \\
\text { Electricity }(388 \mathrm{~kW})\end{array}$ & $\begin{array}{l}\text { Anhydrous ethanol } \\
(4.186 \mathrm{~kg} / \mathrm{s}) \\
\text { Sub-products }(57.50 \mathrm{~kg} / \mathrm{s})\end{array}$ \\
\hline
\end{tabular}

\footnotetext{
a extracted juice split ratio is adjusted in order to comply with a sugar to ethanol production ratio of 2.20

b syrup split ratio is adjusted in order to obtain a $17.6 \%$ by mass sucrose concentration at the inlet of subsystem 6 .
} 
temperature is in the range between 28 and $50{ }^{\circ} \mathrm{C}$ and depends on the type of yeast.

Ethanol is then distilled (subsystem 7) from the liquor near its azeotropic point to obtain hydrous ethanol (95\% ethanol by volume). Further dehydration is necessary when anhydrous ethanol is the desired product. This is nowadays done by means of tertiary azeotropic distillation (adding cycle-hexane) or molecular sieves. However, only hydrous ethanol is produced in the system considered in this paper.

\section{Sugar-cane process modeling}

In this section the concepts for modeling the basic subsystems in Fig. 1 are discussed. The system is modeled in the MATLAB/Simulink environment, where system components are represented by high level blocks (which can be seen as transfer functions) and the input and output signals connecting them are vectors that contain all the physical, thermodynamic and chemical quantities of the mass and energy streams. The mass fraction of solid content in the juice (brix $b$ ) and the mass fraction of pure sucrose in the solid content (purity) are the two parameters used to characterize the sugar-water solution. Thermodynamics properties of the sugarwater solution are estimated using the equations in [19].

\subsection{The sugar-cane process: base case design}

The main assumptions used to model the processes for the conversion of sugar-cane into white sugar and ethanol are taken from previous works $[13,14,20]$, which are based on data reconciliation about an existing plant. The mass flow rate of the input sugar-cane stream is $138.9 \mathrm{~kg} / \mathrm{s}(=500 \mathrm{t} / \mathrm{h})$, its sucrose and bagasse contents being $14 \%$ and $28 \%$ by mass, respectively (purity is $86 \%$ ).

Sugar and ethanol production rates are fixed in the base case scenario to 9.21 and $4.19 \mathrm{~kg} / \mathrm{s}$, respectively. In the following sections two other scenarios with different sugar and ethanol production rates are considered by adjusting the splitting and mixing fractions of juice and syrup. Material and energy streams of the base case scenario are summarized in Table 1, and the list of hot and cold streams is presented in Table 2. The analysis of the MER condition in the base case is presented in Fig. 2, which shows the hot and cold composite curves and grand composite curve. The MER hot utility requirement of the base case scenario is $101660 \mathrm{~kW}$. It is worth mentioning that when different sugar to ethanol production rates are considered in the other two scenarios addressed later, the values reported in Tables 1 and 2 are varied proportionally to the new juice and syrup mass flow rates for all the subsystems except for the multi-effect evaporator, which is in fact subject to synthesis and design optimization. In this subsystem, the energy and mass balances in each effect depend on the pressure level and outlet juice solid concentration (which are decision variables in the optimization), and are therefore evaluated by an appropriate thermodynamic model, which is presented in details in Section 3.2.

The variable(s) affecting system mass balances can be determined by following the paths of juice, syrup and molasses in Fig. 1. The fermenting process needs three main input streams in order to satisfy some specific operating conditions for enhancing the sucrose to ethanol conversion by yeast addition. In particular, the sucrose concentration at fermentor inlet is set to $17.6 \%$ by mass, so that some concentrated juice (syrup) has to be added to the treated juice (sucrose concentration 15\%) to reach the desired concentration. Moreover, the molasses obtained as a sub-product in subsystem 5 are recycled to fermentor inlet in order to convert part of their sucrose content into ethanol. Since molasses production depends on the juice mass flow rate feeding subsystem 5 , the sugar and ethanol production rates are governed by the splitting fractions of juice at the extraction outlet and by the splitting fractions of syrup at the evaporator outlet. However, the concentration requirement at fermentor inlet (17.6\%) imposes a constraint that eliminates one degree of freedom, so that the choice of the splitting ratio at only one split (either juice split or syrup split, see Fig. 1)

Table 2

Thermal streams in the process (base case data).

\begin{tabular}{|c|c|c|c|c|c|c|}
\hline \multirow[t]{2}{*}{ Subsystem } & \multicolumn{3}{|l|}{ Hot streams } & \multicolumn{3}{|l|}{ Cold streams } \\
\hline & Tin & Tout & $\mathrm{Q}[\mathrm{kW}]$ & Tin & Tout & $\mathrm{Q}[\mathrm{kW}]$ \\
\hline \multirow[t]{2}{*}{$1-$} & $50{ }^{\circ} \mathrm{C}(323 \mathrm{~K})$ & $25^{\circ} \mathrm{C}(298 \mathrm{~K})$ & 726 & & & \\
\hline & $50{ }^{\circ} \mathrm{C}(323 \mathrm{~K})$ & $25^{\circ} \mathrm{C}(298 \mathrm{~K})$ & 5805 & & & \\
\hline \multirow[t]{4}{*}{$2-$} & $98{ }^{\circ} \mathrm{C}(371 \mathrm{~K})$ & $98{ }^{\circ} \mathrm{C}(371 \mathrm{~K})$ & 3263 & $39{ }^{\circ} \mathrm{C}(312 \mathrm{~K})$ & $105^{\circ} \mathrm{C}(378 \mathrm{~K})$ & -28704 \\
\hline & $98{ }^{\circ} \mathrm{C}(371 \mathrm{~K})$ & $25^{\circ} \mathrm{C}(298 \mathrm{~K})$ & 434 & & & \\
\hline & $73{ }^{\circ} \mathrm{C}(346 \mathrm{~K})$ & $73^{\circ} \mathrm{C}(346 \mathrm{~K})$ & 478 & & & \\
\hline & $73{ }^{\circ} \mathrm{C}(346 \mathrm{~K})$ & $25^{\circ} \mathrm{C}(298 \mathrm{~K})$ & 41 & & & \\
\hline \multirow[t]{4}{*}{$3-$} & $98^{\circ} \mathrm{C}(371 \mathrm{~K})$ & $98{ }^{\circ} \mathrm{C}(371 \mathrm{~K})$ & 1419 & $39{ }^{\circ} \mathrm{C}(312 \mathrm{~K})$ & $105^{\circ} \mathrm{C}(378 \mathrm{~K})$ & -12446 \\
\hline & $98{ }^{\circ} \mathrm{C}(371 \mathrm{~K})$ & $25^{\circ} \mathrm{C}(298 \mathrm{~K})$ & 189 & & & \\
\hline & $73{ }^{\circ} \mathrm{C}(346 \mathrm{~K})$ & $73^{\circ} \mathrm{C}(346 \mathrm{~K})$ & 208 & & & \\
\hline & $73{ }^{\circ} \mathrm{C}(346 \mathrm{~K})$ & $25^{\circ} \mathrm{C}(298 \mathrm{~K})$ & 18 & & & \\
\hline \multirow[t]{10}{*}{$4-$} & $115^{\circ} \mathrm{C}(388 \mathrm{~K})$ & $115^{\circ} \mathrm{C}(388 \mathrm{~K})$ & 94002 & $115^{\circ} \mathrm{C}(388 \mathrm{~K})$ & $115^{\circ} \mathrm{C}(388 \mathrm{~K})$ & -101220 \\
\hline & $115^{\circ} \mathrm{C}(388 \mathrm{~K})$ & $25^{\circ} \mathrm{C}(298 \mathrm{~K})$ & 15840 & $108^{\circ} \mathrm{C}(381 \mathrm{~K})$ & $108{ }^{\circ} \mathrm{C}(381 \mathrm{~K})$ & -17492 \\
\hline & $108{ }^{\circ} \mathrm{C}(381 \mathrm{~K})$ & $108^{\circ} \mathrm{C}(381 \mathrm{~K})$ & 19271 & $98^{\circ} \mathrm{C}(371 \mathrm{~K})$ & $98^{\circ} \mathrm{C}(371 \mathrm{~K})$ & -19101 \\
\hline & $108{ }^{\circ} \mathrm{C}(381 \mathrm{~K})$ & $25^{\circ} \mathrm{C}(298 \mathrm{~K})$ & 2933 & $84^{\circ} \mathrm{C}(357 \mathrm{~K})$ & $84^{\circ} \mathrm{C}(357 \mathrm{~K})$ & -19976 \\
\hline & $98^{\circ} \mathrm{C}(371 \mathrm{~K})$ & $98^{\circ} \mathrm{C}(371 \mathrm{~K})$ & 20983 & $58^{\circ} \mathrm{C}(331 \mathrm{~K})$ & $58^{\circ} \mathrm{C}(331 \mathrm{~K})$ & -22433 \\
\hline & $98{ }^{\circ} \mathrm{C}(371 \mathrm{~K})$ & $25^{\circ} \mathrm{C}(298 \mathrm{~K})$ & 2773 & & & \\
\hline & $84^{\circ} \mathrm{C}(357 \mathrm{~K})$ & $84{ }^{\circ} \mathrm{C}(357 \mathrm{~K})$ & 22200 & & & \\
\hline & $84^{\circ} \mathrm{C}(357 \mathrm{~K})$ & $25^{\circ} \mathrm{C}(298 \mathrm{~K})$ & 2287 & & & \\
\hline & $58{ }^{\circ} \mathrm{C}(331 \mathrm{~K})$ & $58^{\circ} \mathrm{C}(331 \mathrm{~K})$ & 25415 & & & \\
\hline & $58{ }^{\circ} \mathrm{C}(331 \mathrm{~K})$ & $25^{\circ} \mathrm{C}(298 \mathrm{~K})$ & 1293 & & & \\
\hline \multirow[t]{4}{*}{$5-$} & $71{ }^{\circ} \mathrm{C}(344 \mathrm{~K})$ & $71{ }^{\circ} \mathrm{C}(344 \mathrm{~K})$ & 20742 & $71{ }^{\circ} \mathrm{C}(344 \mathrm{~K})$ & $71{ }^{\circ} \mathrm{C}(344 \mathrm{~K})$ & -21371 \\
\hline & $71{ }^{\circ} \mathrm{C}(344 \mathrm{~K})$ & $25^{\circ} \mathrm{C}(298 \mathrm{~K})$ & 1196 & $70^{\circ} \mathrm{C}(343 \mathrm{~K})$ & $70{ }^{\circ} \mathrm{C}(343 \mathrm{~K})$ & -2969 \\
\hline & $70{ }^{\circ} \mathrm{C}(343 \mathrm{~K})$ & $25^{\circ} \mathrm{C}(298 \mathrm{~K})$ & 146 & $128^{\circ} \mathrm{C}(401 \mathrm{~K})$ & $128^{\circ} \mathrm{C}(401 \mathrm{~K})$ & -441 \\
\hline & $70{ }^{\circ} \mathrm{C}(343 \mathrm{~K})$ & $70^{\circ} \mathrm{C}(343 \mathrm{~K})$ & 2589 & & & \\
\hline \multirow[t]{2}{*}{$6-$} & $93{ }^{\circ} \mathrm{C}(366 \mathrm{~K})$ & $28^{\circ} \mathrm{C}(301 \mathrm{~K})$ & 12549 & & & \\
\hline & $28^{\circ} \mathrm{C}(301 \mathrm{~K})$ & $28^{\circ} \mathrm{C}(301 \mathrm{~K})$ & 4723 & & & \\
\hline \multirow[t]{3}{*}{$7-$} & $68{ }^{\circ} \mathrm{C}(341 \mathrm{~K})$ & $68^{\circ} \mathrm{C}(341 \mathrm{~K})$ & 614 & $78^{\circ} \mathrm{C}(351 \mathrm{~K})$ & $78^{\circ} \mathrm{C}(351 \mathrm{~K})$ & -21212 \\
\hline & $78{ }^{\circ} \mathrm{C}(351 \mathrm{~K})$ & $35^{\circ} \mathrm{C}(308 \mathrm{~K})$ & 531 & $78^{\circ} \mathrm{C}(351 \mathrm{~K})$ & $78^{\circ} \mathrm{C}(351 \mathrm{~K})$ & -13021 \\
\hline & $68{ }^{\circ} \mathrm{C}(341 \mathrm{~K})$ & $68^{\circ} \mathrm{C}(341 \mathrm{~K})$ & 8219 & & & \\
\hline
\end{tabular}



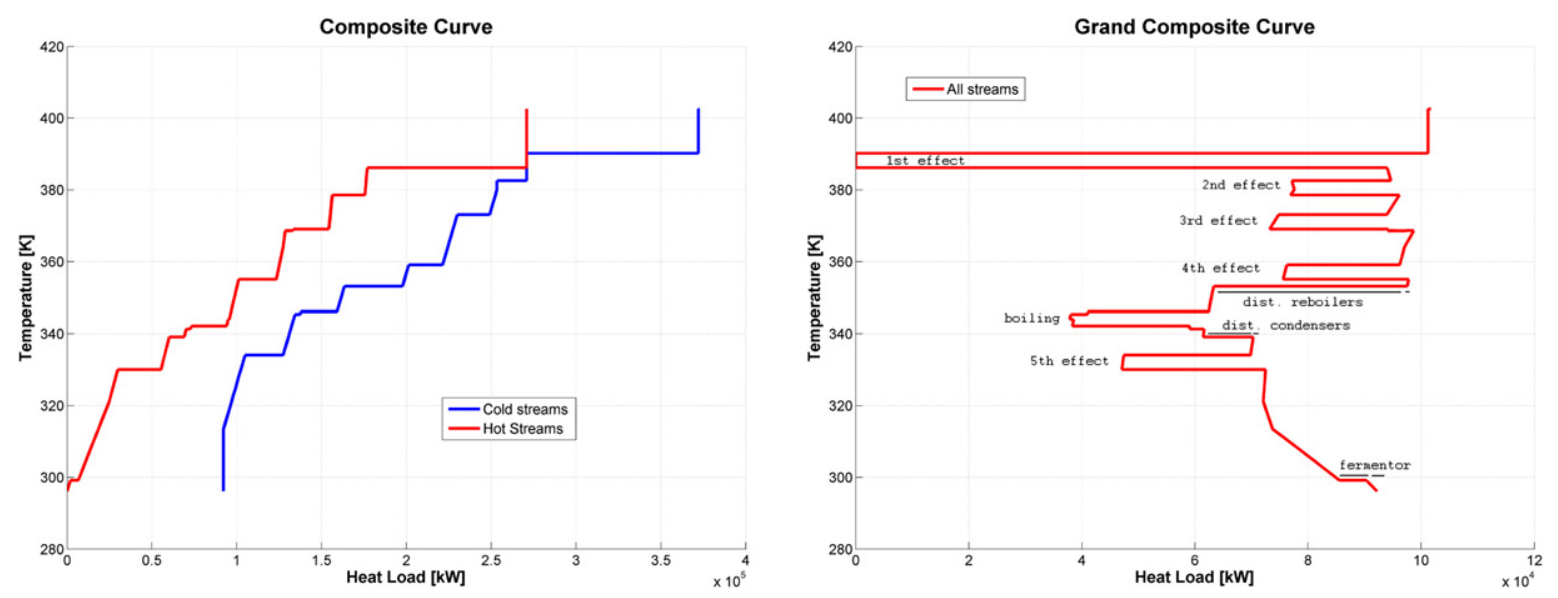

Fig. 2. Base case hot and cold composite curves (left diagram) and grand composite curve (right diagram).

is sufficient to closing system mass balances. This also means that sugar and ethanol production rates cannot assume independent values, but ethanol production may range from $3.29 \mathrm{~kg} / \mathrm{s}$ to $8.52 \mathrm{~kg} / \mathrm{s}$ as sugar production ranges from $11.10 \mathrm{~kg} / \mathrm{s}$ to $0 \mathrm{~kg} / \mathrm{s}$.

\subsection{Multi-effect evaporator model}

The multi-effect evaporator consists of a cascade of units (effects) in which the juice is progressively concentrated up to 65\% by mass of solid content. There are different possible flow configurations of vapor (hot side) and juice (cold side) streams. In the configuration considered in this analysis the two streams flow in the same direction from lower to higher concentrations. A zerodimensional steady state model of a single effect is provided by equations (1), (2) and (3), in which the energy and mass balances are expressed as a function of the effect operating pressure $\left(p_{i}\right)$ and of the increase in solid content concentration $\left(b_{J, i}-b_{J, i-1}\right)$ across the effect (see Fig. 3):

$$
\begin{aligned}
& \dot{M}_{v o, i}=\dot{M}_{J, i} \cdot\left(b_{J, i} / b_{J, i-1}-1\right) \\
& T_{v o, i}=T_{J, i}=T_{s a t}\left(p_{i}\right)+d T_{e v a p} \\
& \dot{M}_{v o, i} \cdot h_{v o, i}+\dot{M}_{J, i} \cdot h_{J, i}=\dot{M}_{J, i-1} \cdot h_{J, i-1}+Q_{i}^{+}
\end{aligned}
$$

Equation (1) is used to evaluate the water mass flow rate evaporating in the i-th effect in order to reach the desired solid concentration $b_{J, i}$. The vapor and the concentrated juice exiting the cold side of each unit ( $V o, i$ and $J, i$, respectively) are assumed to have the same temperature (Equation (2)), which is equal to steam

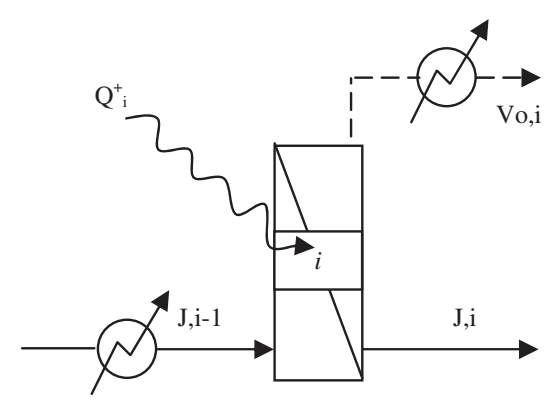

Fig. 3. Mass and energy streams in a unit of the multi-effect evaporator model. saturation temperature at the operating pressure $p_{i}$ of the effect plus the difference in evaporation temperature $d T_{\text {evap }}$ between juice and pure water due to the solid content of the solution. The energy balance in Equation (3) is used to evaluate the heat requirement $Q^{+}{ }_{i}$ of the effect. Equation (4) provides a polynomial expression for evaluating $d T_{\text {evap }}$ as a function of the only solid content at effect outlet (it overestimates $d T_{\text {evap }}$ if compared to the expression found in [21], which takes into account the dependency on effect operating pressure as well):

$d T_{\text {evap }}=3.7 \cdot b_{J, i}-5.8 \cdot b_{J, i}^{2}+18 \cdot b_{J, i}^{3}$

The multi-effect evaporator model is particularly critical because different configurations are explored in following sections by varying the number of units, the concentration levels at the outlet of each effect and the pressure levels of each unit. In fact, most of the heat required by the entire process is used in this subsystem. In counter-current multi-effect evaporators, the heat required by the first unit is usually provided by the steam produced in a boiler and, in general, a higher number of units increases the potential for heat integration among the units and results in a lower heat requirement of the first unit [15]. However, this rule of thumb may not valid when total site heat integration is considered, because the optimal number of units and the optimal operating parameters of the multi-effect evaporator depend on the opportunities for heat integration with all the other system thermal streams. Indeed, this methodology allows to explore all the possible uses of the heat carried by the hot vapor streams (not only in the multi-effect evaporator, but also in the other subsystems) subject to the constraint of heat transfer feasibility.

Three multi-effect evaporator configurations, with three, five and seven units, are considered as design alternatives in the optimization problems defined in following sections, and the choice among them is governed by an integer variable. Each unit generates three thermal streams to be added to the whole set of thermal streams to be integrated: a cold thermal stream associated with the juice boiling $\mathrm{Q}^{+}{ }_{i}$ within the evaporation unit and two hot thermal streams related to condensation and cooling of the steam exiting the unit (a similar modeling approach has been considered in another work [22]). Some operating parameters of the multi-effect evaporator are instead fixed in the analysis:

- The temperature level of the first unit: $105^{\circ} \mathrm{C}$;

- The syrup solid content at multi-effect evaporator outlet: $65 \%$ by mass;

- The minimum operating pressure of the last unit: 0.2 bar. 


\section{Minimum hot utility requirement of the sugar-cane conversion process}

This section presents the results of the minimization of the process hot utility requirement for three pairs of values of sugar and ethanol production rates. The set of the hot and cold streams of the sugar-cane process only, which are listed in Fig. 4 using the conventional black-box representation, are integrated for a given minimum temperature difference without assuming a predefined heat exchanger network configuration. Fig. 4 also shows a flow-chart about the overall optimization procedure in which the heat integration step is included. The minimum process heat requirement is evaluated as the result of a linear programming problem since, according to Pinch Analysis rules, the heat transfer feasibility of the thermal cascade can be expressed as a set of linear inequality constraints (no cumulated heat deficit load at any temperature level of the thermal cascade). This evaluation clearly depends on the values assigned to the intensive quantities belonging to the decision variable set, which usually have a strongly non-linear relationship with the optimization objective function. Accordingly, the optimization procedure consists of two nested levels: at the outer level the intensive parameters (pressures and temperatures of the multi-effect evaporator) are optimized by an evolutionary algorithm, while at the inner level the hot utility mass flow rate is minimized by linear programming. Although evolutionary algorithms are particularly time consuming compared to other optimization strategies, they better deal with discontinuous search spaces, in particular when integer variables are involved. Most of the problems related to the heat integration of a complex set of thermal streams feature this kind of search space, the optimal solution being likely to activate one or more constraints of the heat integration problem (typically one or more pinch points).

Process analysis and optimization are carried out using a set of numerical tools developed at LENI. An interface platform (OSMOSE [23]) recalls process parameters from Simulink, organizes the information and provides the required data to the heat integration software (EASY), which analyzes the heat cascade and evaluates the minimum hot utility consumption. The evolutionary optimization is carried out in the Matlab environment using the MOO algorithm code [24].

The optimization problem is set as follows:

$\min f(\bar{x})$

( $f$ returns the MER hot utility requirement of the sugar-cane process)

with respect to the set of the following decision variables $\bar{x}$ :

- $n_{U N I T}$, an integer variable $\left(n_{U N I T} \in\{3,5,7\}\right)$ indicating the number of units in the multi-effect evaporator configuration;

- $\Delta b_{i}$, the increments of solid content concentration in the $i$-th evaporation unit (they are $n_{U N I T}-1$ variables, since the solid concentration at the last unit is set to $65 \%$ ); if $n_{U N I T}=3$ :

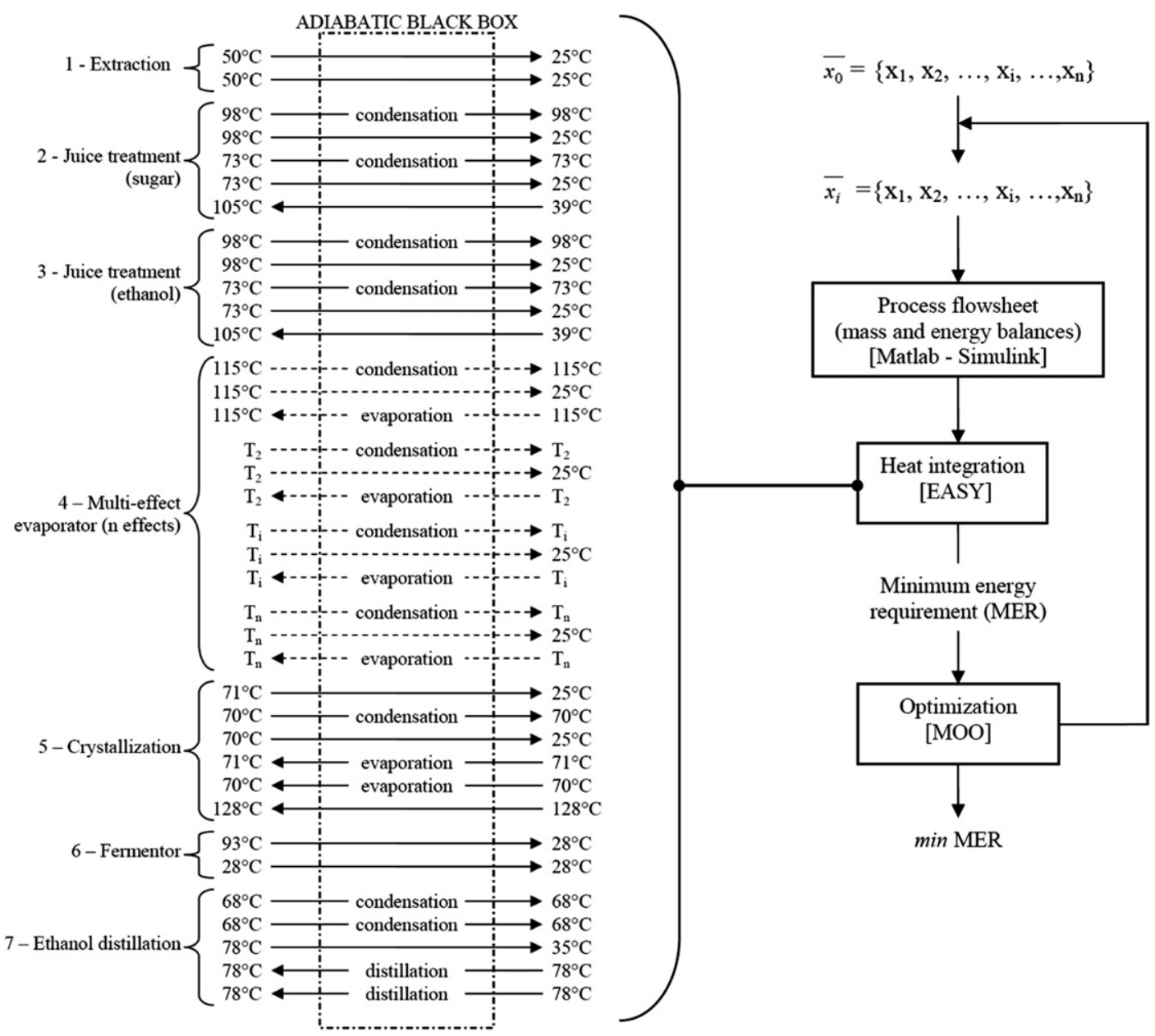

Fig. 4. Algorithm used for the calculations and heat integration problem (OSMOSE platform). 
$\Delta b_{1} \in[2,20], \Delta b_{2} \in[7,30] ;$ if $n_{U N I T}=5: \Delta b_{1} \in[2,10], \Delta b_{2} \in[4,12]$, $\Delta b_{3} \in[5,14], \Delta b_{4} \in[6,15] ;$ if $n_{U N I T}=7: \Delta b_{1} \in[2,7], \Delta b_{2} \in[2,7]$, $\Delta b_{3} \in[2,8], \Delta b_{4} \in[2,9], \Delta b_{5} \in[2,10], \Delta b_{6} \in[2,10]$. These variables directly affect the heat loads required by the effects.

- $\Delta T_{i, i+1}$, the temperature differences between the $i$-th and the $i+1$ th evaporation units (they are $n_{U N I T}-1$ variables, since the first unit is considered to operate at $\left.105^{\circ} \mathrm{C}\right) ; \Delta T_{i, i+1} \in[-10 ;-5]^{\circ} \mathrm{C}$. These variables directly affect the operating pressures of the effects.

The minimum allowable temperature difference $\Delta T_{\min }$ for heat transfer feasibility is set equal to $4{ }^{\circ} \mathrm{C}$.

The optimal grand composite curves for the three cases with different sugar and ethanol production rates are shown in Figs. 5 and 6 , and 7 . The minimum heat demand with base case sugar and ethanol production rates is reduced by 39\%, from $101660 \mathrm{~kW}$ (base case in Fig. 2) to $62378 \mathrm{~kW}$ (case 1 in Fig. 5). This can be justified by two main reasons. Comparing Figs. 2 and 5 , it is apparent that the distribution of the heat loads among the units of the multi-effect evaporator is significantly different. The base case GCC in Fig. 2 shows that the heat load of the first unit is equal to the whole process heat requirement and much greater than those of the other four units. This means that in the first unit a high increment of solid content concentration is achieved $\left(\Delta b_{1}=9.9\right)$ and a high steam mass flow rate is separated from the juice. The large excess of steam made available in this way is then used in the base case design to heat all the other cold streams of the process, while the steam generated in the other units is mainly used for a local heat integration within the multi-effect evaporator subsystem. This design choice should reduce the number of stream matches in the heat exchangers networks. On the contrary, the optimal GCC in Fig. 5 shows that the heat load of the first unit is much lower $\left(\Delta b_{1}\right.$ is only 2) and comparable with those of the other four units. This is because all the streams of the multi-effect evaporator subsystem are now fully integrated with the other thermal stream of the process at system level. The other significant difference is that the operating pressures of the units are higher than those in the base case design (i.e. the optimal temperature differences between subsequent evaporation effects are lower). In Fig. 5 the optimal temperature of the last effect is higher than that of the crystallization subsystem and this allows all the heat of evaporation in the heat cascade to be exploited.

Figs. 5 to 7 also show that the process pinch point moves from the temperature level of the first evaporation unit $\left(105^{\circ} \mathrm{C}=378 \mathrm{~K}\right)$ in the base case configuration (Fig. 3), down to the temperature level of the crystallization process $\left(71^{\circ} \mathrm{C}=344 \mathrm{~K}\right)$ in all the three optimized configurations. Although parts of the GCC are modified depending on the sugar and ethanol production rates, the heat demand for distillation (i.e. ethanol production) is the most significant quantity affecting process energy requirement in all the three cases.

It is worth noting that because of the optimal location of the pinch point there are actually many multi-effect evaporator configurations that can be regarded as optimal according to the chosen thermodynamic objective. In fact, if the temperature levels of the thermal streams associated with the multi-effect evaporator are all above the pinch point, the MER hot utility can be minimized in several different ways by adjusting the number of effects and their heat loads (through $\Delta b_{i}$ ) and operating pressures (through $\left.\Delta T_{i, i+1}\right)$. Solutions with 5 and 7 effects other than those reported in Figs. 5 to 7 are possible, but are not presented here for sake of brevity. Although increasing the number of effects from 5 to 7 does not clearly provide any economical benefit, the convenience of choosing different values for the other parameters could be assessed only by an economic analysis, which is beyond the scope of this paper.

\section{Maximum net electricity generation in a combined sugar, ethanol and electricity production plant}

In this Section the thermal integration of a bagasse fuelled CHP system with the sugar-cane conversion process is analyzed to assess the resulting total site net power generation potential. The use of bagasse, which is the main process sub-product, as an energy source is being extensively studied in sugar-cane industry. In fact, the chemical energy rate available from the combustion of all the bagasse extracted from the input sugar-cane stream is far greater than the process heat and power demand, so that the considerably large excess of the electricity produced can be sold to the market, thereby increasing the profitable use of the raw cane. In particular, combustion or gasification are the common ways of recycling this sub-product after a drying process [25-27], although methanation or additional ethanol production via enzymatic hydrolysis are new promising alternatives. The improvement of ethanol production from bagasse is under investigation [28-30]. The integration of ethanol production and bagasse conversion processes has been studied in [31] and features the conversion of bagasse into natural gas instead of electricity.

An optimization problem of different nature is addressed in this section. The objective to be maximized is now total site net power production (i.e. the power generated by the CHP system minus the power requirement of the sugar-cane conversion process) considering the thermal streams of the process and those of the CHP system as a whole set of streams to be integrated (Fig. 8). The results in Section 4, in which heat integration was limited to the thermal streams of the process only, have already provided a general indication about the heat load that the CHP system should supply to the process. Nevertheless the several near-optimal solutions that were found to minimize process hot utility requirement are no longer equivalent in this new optimization problem, since the potential for total site net power production depends not only on the amount of heat cascaded through the whole set of thermal streams, but also on the temperature level at which the excess heat is available for power generation. Decision variables are the process synthesis and design parameters that were already considered in Section 4 with the addition of the design parameters of the CHP system.

In Sections 5.1 and 5.2 two different CHP concepts are considered: a bagasse fuelled steam boiler with a steam cycle and a bagasse integrated gasification combined cycle, respectively. The first CHP configuration refers to the conventional choice in which direct combustion of the bagasse provides heat for steam generation. In the second configuration the bagasse is gasified and then the obtained syngas is used to fuel a gas turbine, while the heat from different hot sources (mainly gas turbine exhaust gases and syngas cleaning section) is used to produce steam for a bottoming cycle. In both configurations steam extraction from the steam turbine is considered, in order to covering the heat requirement of the sugar-cane conversion process with the steam drawn off at an intermediate stage, which separates the high pressure turbine section from the low pressure one. The remaining part of the steam is expanded to a lower pressure level and condensed either by providing additional heat to the process (at a lower temperature level than the first steam draw-off) or by a cold utility. The option of using vapor recompression to increase the fraction of combustion heat used for power generation is also discussed in Section 5.3.

As in Section 4, a two-level hybrid optimization strategy is used to solve the synthesis and parameter optimization problem (see Fig. 9). According to this strategy the decision variables are separated into two sets which are optimized in the two nested optimization steps, using a genetic algorithm for the outer optimization and linear programming for the inner optimization. The first set comprises the variables associated with intensive structural 


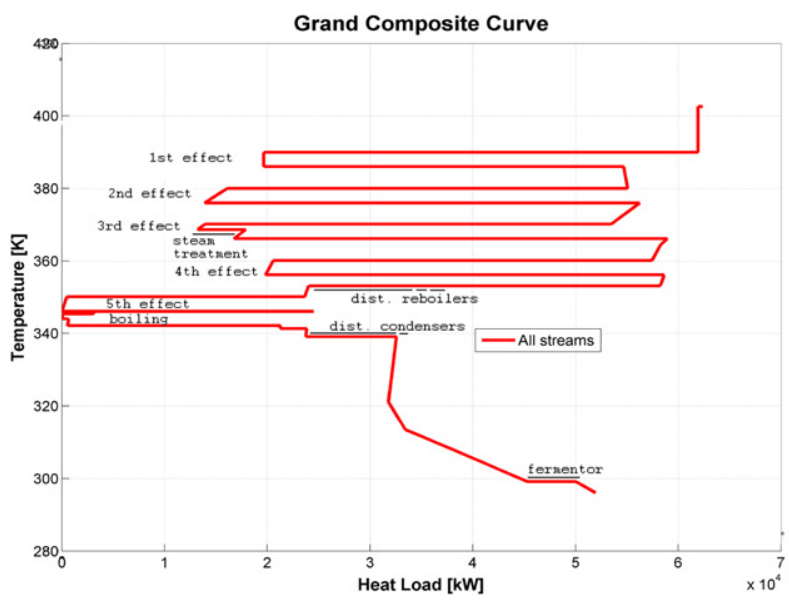

Case 1 results

(ethanol: $4.19 \mathrm{~kg} / \mathrm{s}$; sugar: $9.21 \mathrm{~kg} / \mathrm{s}$ )

Hot utility: $62378 \mathrm{~kW}$

Number of effects: 5

Solid concentrations at evap. units outlet: $b_{1}=17.0 \% ; \quad b_{2}=21.7 \% ; \quad b_{3}=29.7 \%$; $b_{4}=44.7 \%$

Unit pressures: $p_{2}=1.17 \mathrm{bar} ; \quad p_{3}=0.81 \mathrm{bar} ; \quad p_{4}=0.53 \mathrm{bar}$; $p_{5}=0.31$ bar;

Fig. 5. Case 1 grand composite curve (ethanol: 4.19 kg/s; sugar: 9.21 kg/s).

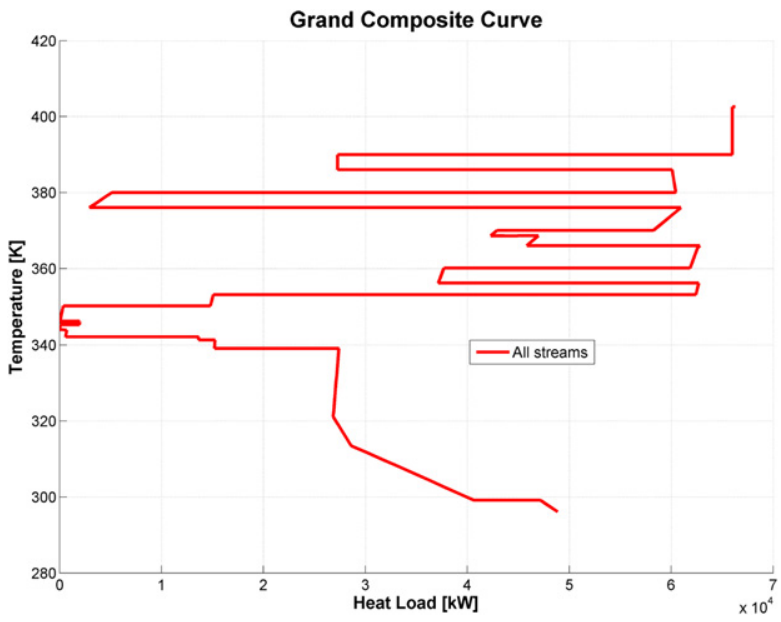

Case 2 results

(ethanol: $5.79 \mathrm{~kg} / \mathrm{s}$; sugar: $5.79 \mathrm{~kg} / \mathrm{s}$ )

Hot utility: $66274 \mathrm{~kW}$

Number of effects: 5

Solid concentrations at unit outlet:

$b_{1}=17.5 \% ; \quad b_{2}=27.8 .0 \% ; \quad b_{3}=33.5 \%$;

$b_{4}=48.1 \%$;

Unit pressures:

$p_{2}=1.16 \mathrm{bar} ; \quad p_{3}=0.80 \mathrm{bar} ; \quad p_{4}=0.53 \mathrm{bar}$; $p_{5}=0.31 \mathrm{bar}$

Fig. 6. Case 2 grand composite curve (ethanol: $5.79 \mathrm{~kg} / \mathrm{s}$; sugar: $5.79 \mathrm{~kg} / \mathrm{s}$ ).

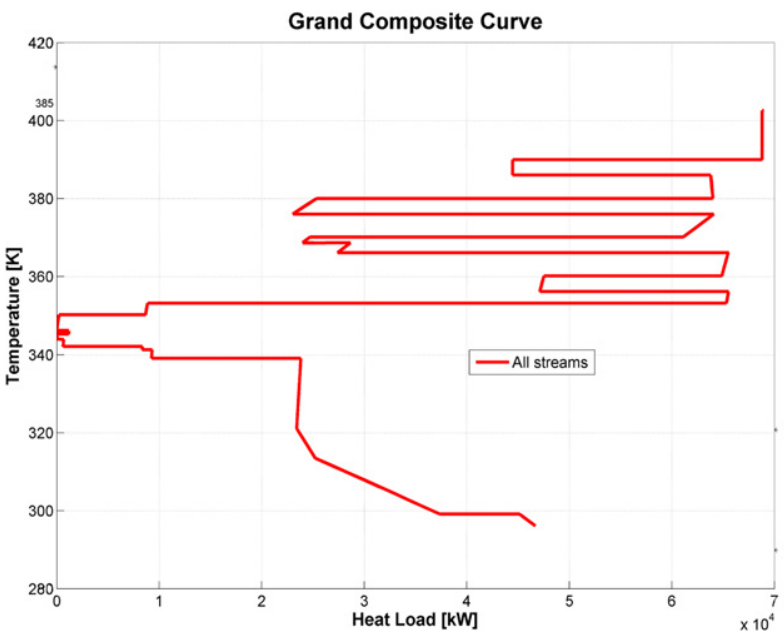

Case 3 results

(ethanol: $6.90 \mathrm{~kg} / \mathrm{s}$; sugar: $3.43 \mathrm{~kg} / \mathrm{s}$ )

Hot utility: $68961 \mathrm{~kW}$

Number of effects: 5

Solid concentrations at unit outlet:

$b_{1}=16.4 \% ; \quad b_{2}=23.2 \% ; \quad b_{3}=37.2 \%$;

$b_{4}=52.2 \%$;

Unit pressures:

$p_{2}=1.17 \mathrm{bar} ; \quad p_{3}=0.80 \mathrm{bar} ; \quad p_{4}=0.51 \mathrm{bar}$; $p_{5}=0.31 \mathrm{bar}$

Fig. 7. Case 3 grand composite curve (ethanol: $6.90 \mathrm{~kg} / \mathrm{s}$; sugar: $3.43 \mathrm{~kg} / \mathrm{s}$ ). 


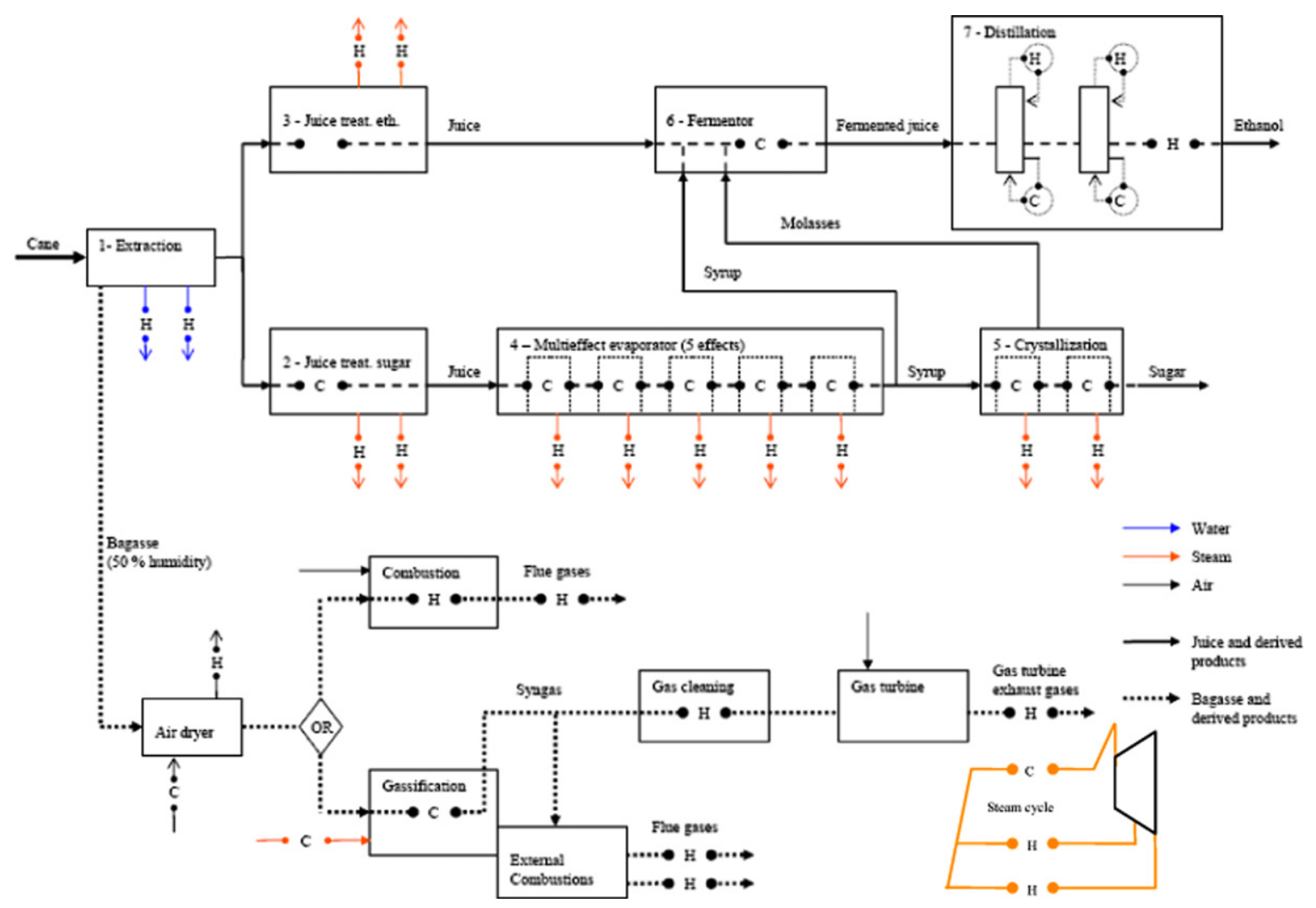

Fig. 8. Schematic representation of hot and cold flows in the sugar-cane conversion process and CHP systems.

and design parameters of the process and the CHP system. The second set of decision variables includes all the mass flow rates of the steam Rankine cycle of the CHP system. In this inner step, the steam mass flow rates are optimized for given "frozen" values assigned to the variables belonging to the first set (outer optimization step), the objective function (net power production) being a linear function of the steam mass flow rates only. The heat transfer feasibility constraint related to the whole set of thermal streams (process plus CHP system thermal streams) is imposed by means of a number of inequality constraints that are linear in the steam mass flow rates as well, according to Pinch Analysis rules (no cumulated heat deficit load at any temperature level of the thermal cascade). This allows the inner optimization level to be handled by a linear programming algorithm, whereas the outer level is managed by an evolutionary algorithm. This two-level strategy also avoids the fruitless evaluation of a high number of solutions featuring unfeasible combinations of steam mass flow rate values.

Process analysis and optimization are performed by the same numerical tools developed at LENI already used in Section 4. The communication platform OSMOSE interfaces the Simulink model of the system, the outer level evolutionary algorithm (MOO) and the heat integration software (EASY). In this case, EASY is used to evaluate the optimal steam mass flow rates that maximize total site net power production. In fact, this software embeds linear models of steam networks and refrigeration cycles which allow a fast evaluation of their mass balances with little errors compared to more rigorous non-linear models [32,33].

\subsection{Bagasse combustion in steam cycle boiler}

The CHP configuration analyzed in this section uses bagasse combustion to generate the steam driving a steam turbine with one extraction.
As shown in Figs. 1 and 8, bagasse is removed from the cane during the juice extraction process. According to the data found in [14], $28 \%$ by mass of the raw cane is bagasse with $50 \%$ moisture content. The average dry-based composition of bagasse is C (47\%), $\mathrm{H}(6.5 \%), \mathrm{O}$ (44\%), ash (2.5\%) [15]. The higher heating value of bagasse used in the calculation is $19137 \mathrm{~kJ} / \mathrm{kg}$ dry basis, and corresponds to a lower heating value of $7646 \mathrm{~kJ} / \mathrm{kg}$ at $50 \%$ mass basis humidity according to the empirical correlation found in [34]. The thermal power available from the combustion of the bagasse mass flow rate discarded from the sugar-cane conversion process is therefore of $297450 \mathrm{~kW}$ (based on LHV at $50 \%$ humidity).

A drying process is however required before combustion because of the high water content. Even though it is possible to use combustion gases as the drying agent, a rotary kiln air drier is considered here. This allows bagasse drying and bagasse combustion to be modeled as independent subsystems, which otherwise would share a material stream. This enhances simulation convergence and provides at the same time a good estimation of the net heat load available from bagasse drying and combustion. Two thermal streams are generated within the bagasse drying subsystem: a cold stream related to environmental air heating up to $200{ }^{\circ} \mathrm{C}$ before entering the drying process and the hot stream of the exhaust air at the drier outlet that can be cooled down to the environmental temperature for heat recovery (see Table 3 ). Bagasse is dried from $50 \%$ to $25 \%$ moisture content, then it is sent to the boiler where is burnt with 0.3 air excess. Bagasse combustion results in $171 \mathrm{~kg} / \mathrm{s}$ of combustion flue gases with an average specific heat of $1.14 \mathrm{~kJ} / \mathrm{kg}-\mathrm{K}$ and the following mass fractions: $65.4 \% \mathrm{~N}_{2}, 4.6 \%$ $\mathrm{O}_{2}, 10.4 \% \mathrm{H}_{2} \mathrm{O}$ and $19.6 \% \mathrm{CO}_{2}(33.52 \mathrm{~kg} / \mathrm{s})$. The combustion gases heat profile is split into two parts: heat is considered to be transferred by radiation above $1000{ }^{\circ} \mathrm{C}$ and by convection under the same temperature, that so the thermal profile of the combustion gases is divided into two parts: an horizontal thermal stream for 
CHP system 1

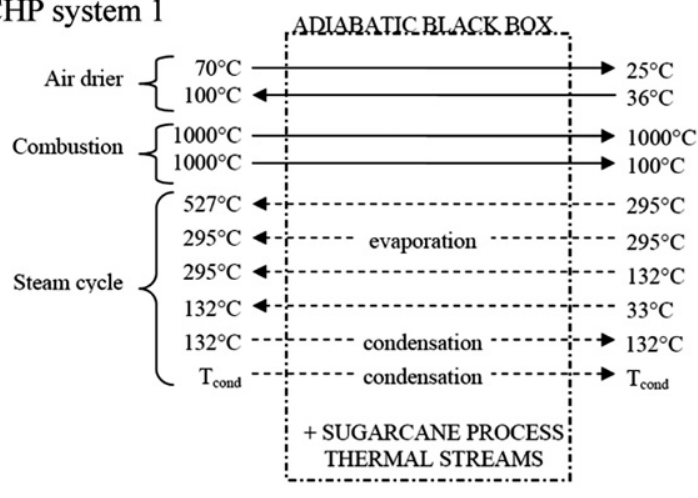

CHP system 2

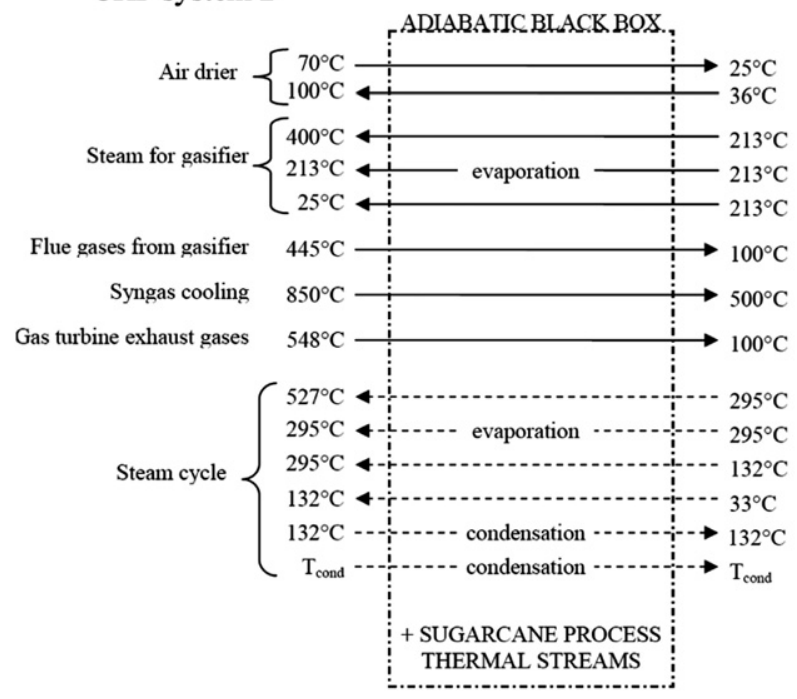

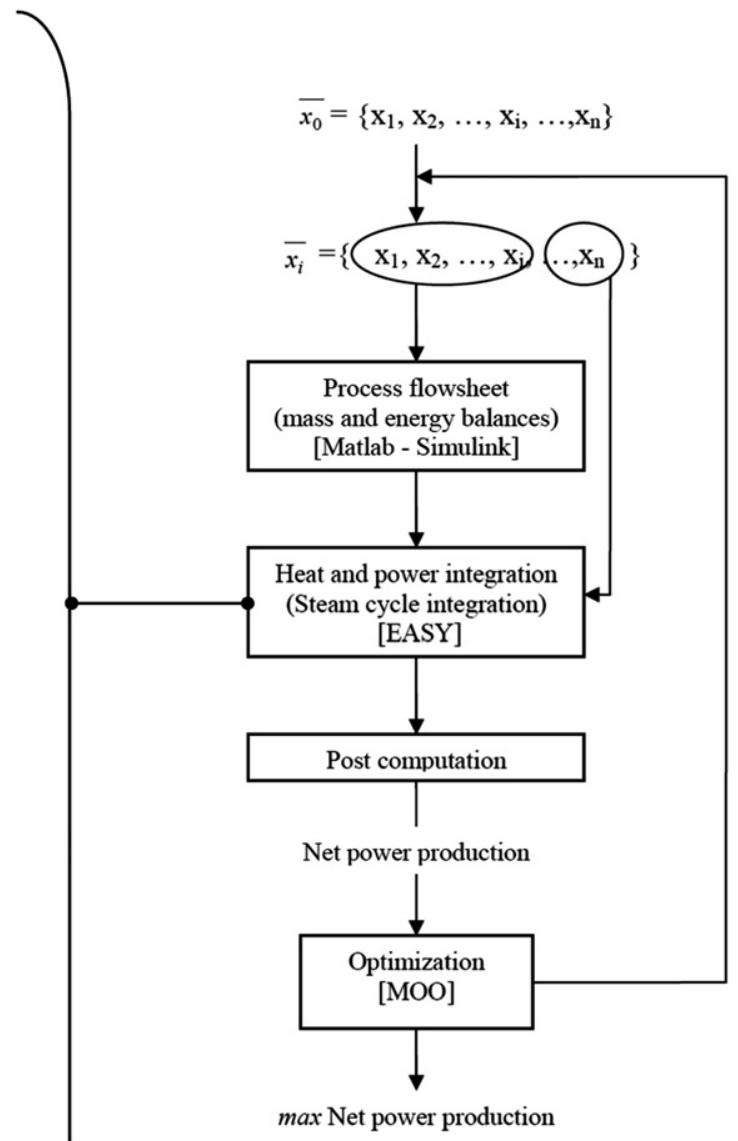

$\max$ Net power production

Fig. 9. Algorithm used for the calculations and heat integration problem (OSMOSE platform).

the radiative part (at $1000^{\circ} \mathrm{C}$ ) and an oblique thermal stream (from $1000{ }^{\circ} \mathrm{C}$ down to $170{ }^{\circ} \mathrm{C}$ ) for the convective part (see Table 3).

Steam is generated at 100 bar and superheated up to $527{ }^{\circ} \mathrm{C}$. Extraction pressure (1.92 bar) is conveniently chosen at the temperature level of the saturated steam that supplies heat to the first effect of the evaporator subsystem $\left(105^{\circ} \mathrm{C}\right)$, which is also the highest temperature level at which heat is required by the sugar-cane process. Steam turbine discharge pressure is a decision variable (included in the first optimization level) and is determined as a result of the optimization procedure. In fact, it is not clear if expanding to the cold utility level is more convenient than expanding to an intermediate level in order to heat-up other parts of the process at temperatures below than that of the first evaporation effect. Accordingly, the second part of the expansion may occur either in a conventional condensing turbine or in a backpressure turbine. The lower bound to discharge pressure is set to 0.1 bar to ensure a sound approach temperature in the cooling tower, assuming that cooling water at $30{ }^{\circ} \mathrm{C}$ can be heated up to

Table 3

Thermal streams of the drying and combustion section.

\begin{tabular}{lccclllll}
\hline Subsystem & \multicolumn{2}{l}{ Hot streams } & & \multicolumn{3}{l}{ Cold streams } \\
\cline { 2 - 4 } & Tin $[\mathrm{K}]$ & Tout $[\mathrm{K}]$ & $\mathrm{Q}[\mathrm{kW}]$ & & Tin $[\mathrm{K}]$ & Tout $[\mathrm{K}]$ & $\mathrm{Q}[\mathrm{kW}]$ \\
\hline Air-drier & 343 & 298 & 39190 & & 309 & 473 & -43440 \\
Combustion & 1273 & 1273 & 152080 & & & \\
& 1273 & 443 & 162720 & & & \\
\hline
\end{tabular}

$35^{\circ} \mathrm{C}$. Steam turbine isentropic efficiencies are set to 0.78 for both the high pressure and low pressure sections.

The optimization problem is set as follows:

$\max f(\bar{x})$

( $f$ returns the total site net power production) where $(\bar{x})$ is the vector including the following decision variables:

- $n_{U N I T,}$ an integer variable $\left(n_{U N I T} \in\{3,5,7\}\right)$ indicating the number of units in the multi-effect evaporator configuration;

- $\Delta b_{i}$, the increments of solid content concentration in the $i$-th evaporation unit (they are $n_{U N I T-1}$ variables, since the solid concentration at the last unit is set to $65 \%$ ); if $n_{U N I T}=3$ : $\Delta b_{1} \in[2,20], \Delta b_{2} \in[7,30] ;$ if $n_{U N I T}=5: \Delta b_{1} \in[2,10], \Delta b_{2} \in[4,12]$, $\Delta b_{3} \in[5,14], \Delta b_{4} \in[6,15] ;$ if $n_{U N I T}=7: \Delta b_{1} \in[2,7], \Delta b_{2} \in[2,7]$, $\Delta b_{3} \in[2,8], \Delta b_{4} \in[2,9], \Delta b_{5} \in[2,10], \Delta b_{6} \in[2,10]$.

- $\Delta T_{i, i+1}$, the temperature differences between the $i$-th and the $i+1$-th evaporation units (they are $n_{U N I T^{-}} 1$ variables, since the first unit is considered to operate at $\left.105^{\circ} \mathrm{C}\right) ; \Delta T_{i, i+1} \in[-10 ;-5]^{\circ} \mathrm{C}$. - $p_{\text {out: }}$ steam turbine discharge pressure; $p_{\text {out }} \in[0.1 ; 1.92]$ bar.

- $\dot{m}_{j}$ : steam mass flow rates (optimized by the inner linear programming algorithm).

Optimization results are shown given in Figs. 10, 11 and 12 for the considered three pairs of sugar and ethanol production rates (Fig. 10 refers to the base case one). Total site heat integration is 


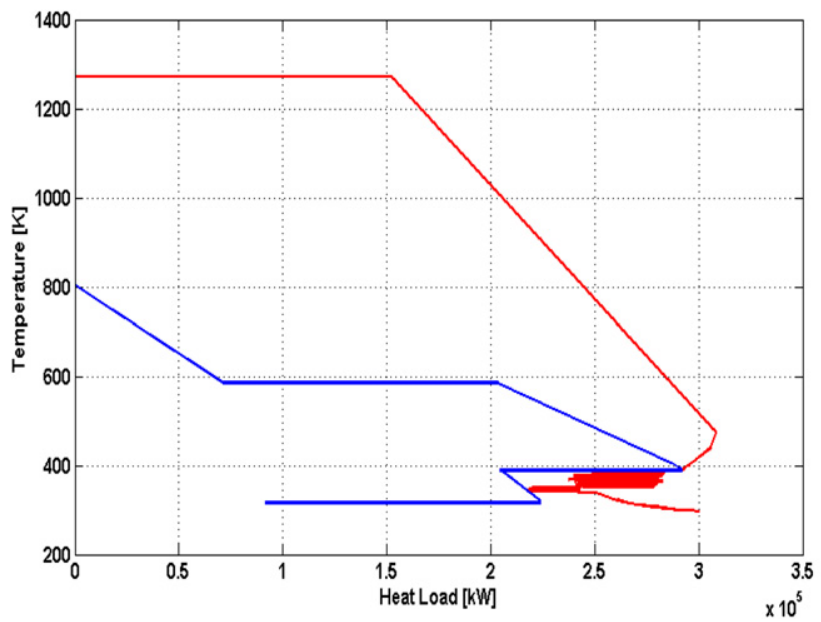

Case 1 results - CHP system 1 (ethanol: $4.19 \mathrm{~kg} / \mathrm{s}$; sugar: $9.21 \mathrm{~kg} / \mathrm{s}$ )

Rankine cycle net power $=91498 \mathrm{~kW}$ HP turbine section power $=\quad 71462 \mathrm{~kW}$ LP turbine section power $=21054 \mathrm{~kW}$ Process power requirement $=15165 \mathrm{~kW}$ Total site net power $=\quad 76333 \mathrm{~kW}$ $\left(152.66 \mathrm{kWh} / \mathrm{t}_{\text {cane }}\right)$

Cold utility requirement $=205952 \mathrm{~kW}$ Bagasse input power $=\quad 297450 \mathrm{~kW}$ Total site net thermal efficiency $=25.66 \%$

Fig. 10. Case 1: integrated grand composite curve with CHP system 1 (ethanol: 4.19 kg/s; sugar: $9.21 \mathrm{~kg} / \mathrm{s}$ ).

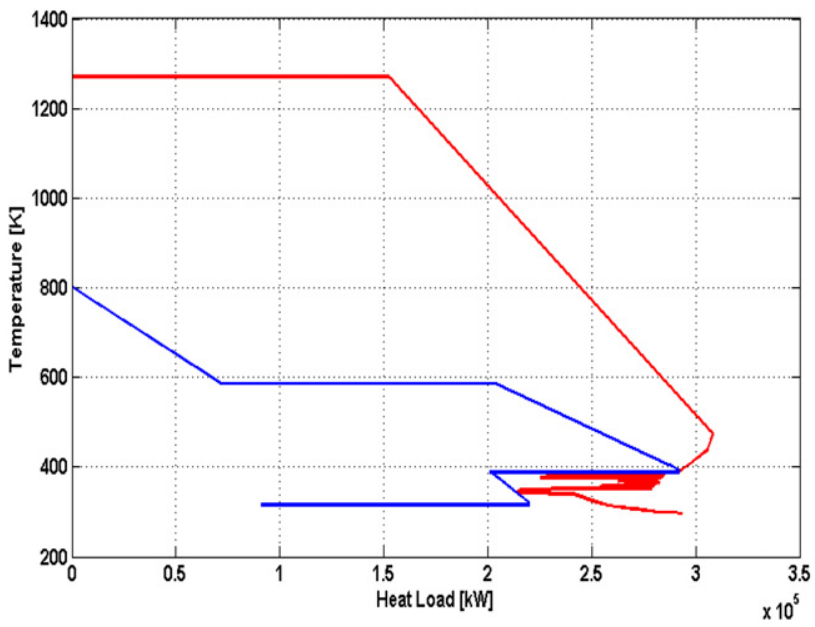

Case 2 results - CHP system 1 (ethanol $5.79 \mathrm{~kg} / \mathrm{s}$; sugar: $5.79 \mathrm{~kg} / \mathrm{s}$ )

Rankine cycle net power $=$ $90897 \mathrm{~kW}$ HP turbine section power $=$ $71509 \mathrm{~kW}$ LP turbine section power $=20497 \mathrm{~kW}$ Process power requirement $=14066 \mathrm{~kW}$ Total site net power $=$ $76831 \mathrm{~kW}$ $\left(153.66 \mathrm{kWh} / \mathrm{t}_{\text {cane }}\right)$

Cold utility requirement $=206553 \mathrm{~kW}$ Bagasse input power $=\quad 297450 \mathrm{~kW}$ Total site net thermal efficiency $=25.82 \%$

Fig. 11. Case 2: integrated grand composite curve with CHP system 1 (ethanol: $5.79 \mathrm{~kg} / \mathrm{s}$; sugar: $5.79 \mathrm{~kg} / \mathrm{s}$ ).

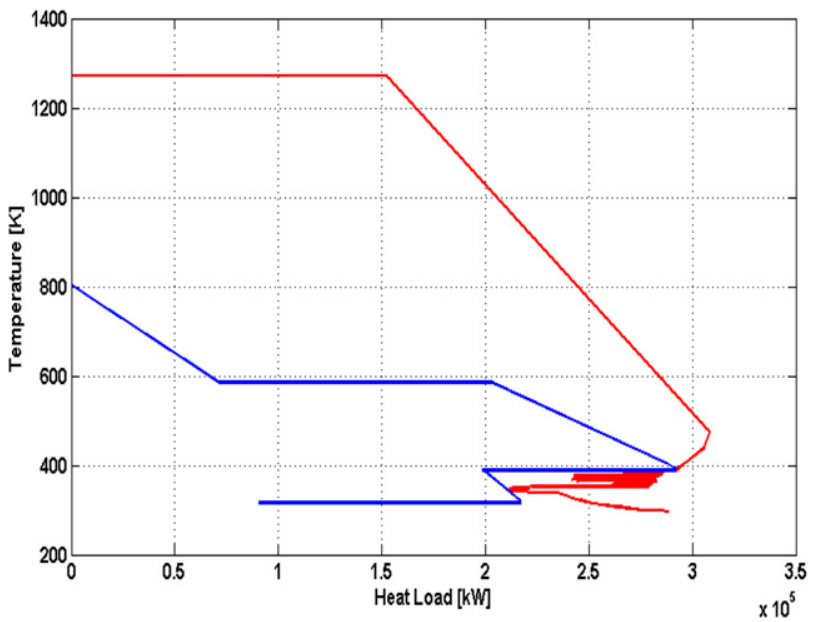

Case 3 results - CHP system 1 (ethanol: $6.90 \mathrm{~kg} / \mathrm{s}$; sugar: $3.43 \mathrm{~kg} / \mathrm{s}$ )

Rankine cycle net power $=$ $90635 \mathrm{~kW}$ HP turbine section power $=$ $71542 \mathrm{~kW}$ LP turbine section power $=20113 \mathrm{~kW}$ Process power requirement $=13301 \mathrm{~kW}$ Total site net power $=$ $77334 \mathrm{~kW}$ $\left(154.67 \mathrm{kWh} / \mathrm{t}_{\text {cane }}\right)$

Cold utility requirement $=206815 \mathrm{~kW}$ Bagasse input power $=\quad 297450 \mathrm{~kW}$ Total site net thermal efficiency $=26.00 \%$

Fig. 12. Case 3: integrated grand composite curve with CHP system 1 (ethanol: $6.90 \mathrm{~kg} / \mathrm{s}$; sugar: $3.43 \mathrm{~kg} / \mathrm{s}$ ). 
shown by means of the so-called integrated grand composite curves, which highlight by different colors the contributions of separate subsets of thermal streams to the total site heat cascade. In Figs. 10, 11 and 12 the steam cycle thermal profiles are shown in blue while all the other thermal streams (bagasse drying, combustion and process thermal streams) are shown in red.

Maximum power generation was obtained when steam turbine discharge pressure reaches its lower bound ( 0.1 bar), and the utility pinch point (the point of the thermal cascade where the process thermal streams are at minimum temperature difference with those of the steam cycle) is at crystallization temperature level ( $71^{\circ} \mathrm{C}=344 \mathrm{~K}$ ), the same of the process pinch point found in the previous optimization (cases in Figs. 5, 6 and 7). Apparently, expanding to the lowest steam discharge pressure (which is equivalent to maximizing steam cycle thermal efficiency) is more convenient in order to maximize the chosen thermodynamic objective function. On the contrary, only sub-optimal solutions are obtained if the expansion is halted at an intermediate pressure level in order to exploit one of the so-called heat pockets in the process heat cascade. A heat pocket is a temperature interval in which heat is made available mostly in the upper part of the interval and requested mostly in the lower part of the interval, so that a direct thermodynamic cycle can profitably operate within it (see the red curve in Fig. 13). The only way to better exploit an heat pocket in the cascade is to add a steam extraction from the turbine (supplying heat to the lower part of the pocket) and to preheat the feedwater between different pressure levels with some heat from the process (draining heat from the upper part of the pocket), for instance part of the heat made available by the steam from the evaporation effects.

In the integrated grand composite curve representation this would be shown by a "triangular" shape of the red curve, resulting from the composition of thermal profiles of the evaporation effects, that perfectly accommodates the oblique line of the blue curve, corresponding to water heating, as in Fig. 13. Although such a design solution may increase power generation, it is also likely to dramatically increase the complexity of the heat exchanger network required to achieve such tight total site heat integration. Thus, the solutions presented in Figs. 10, 11 and 12 should be more viable and profitable than possible more complex and thermodynamically efficient solutions featuring more than one steam extraction.

The optimal solutions obtained with just one steam extraction also show that a reduction of the evaporator heat demand obtained by increasing the number of effects may be pointless, because the heat cascade in the multi-effect evaporator does not affect the

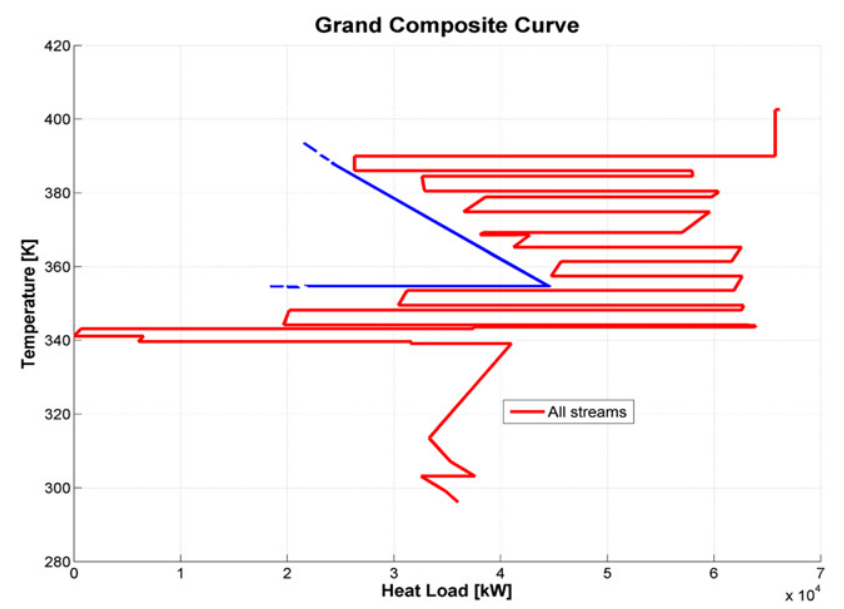

Fig. 13. A steam network exploiting the heat pocket generated by the multi-effect evaporator. thermal integration between the CHP system and the process. For this reason the optimal values of the multi-effect evaporator design parameters found in Section 4 (i.e. those minimizing the process MER) are found as well in the heat integration among the steam cycle, the combustion gases and the sugar-cane conversion process. Even with a larger multi-effect evaporator heat demand, the steam extracted in the solutions presented in Figs. 10,11 and 12 would be still sufficient to cover the process heat demand as long as all the excess heat from the evaporation effects is cascaded down to the crystallization temperature level.

When sugar and ethanol production rates are varied, the mechanical power required by the process changes from 13300 to $15150 \mathrm{~kW}$ (the power consumption of the sugar-cane process is mainly concentrated in the extraction subsystem and, therefore, is only slightly affected by the change in the sugar and ethanol production rates). As a result, only small variations in total site power production (76.3 to $77.3 \mathrm{MW}$ ) are observed among the three cases, since the amount of mechanical power obtained from bagasse combustion is much higher than the mechanical power required by the process. Total site net thermal efficiency is calculated as the ratio between total site net power and bagasse chemical energy rate.

It is worth mentioning that a CHP system designed for the combustion of all the bagasse extracted from the input sugar-cane stream can easily represent the largest share of total site capital costs. This leads to consider the scenario in which only the bagasse required to cover the process hot utility demand is burnt and some power is still produced. The optimization result for this scenario is given in Fig. 14 for the base case values of sugar and ethanol production rates. The optimal CHP system consists of a back-pressure turbine with one extraction and no steam is condensed at the cold utility level. Steam turbine discharge is now at a higher pressure $(0.47 \mathrm{bar})$ that corresponds to crystallization temperature level. The combustion of only $30.2 \%$ of the input bagasse is sufficient in this case. The resulting steam cycle thermal efficiency is $25.12 \%$, with a decrease of about 5 points with respect to the case in which $100 \%$ of the input bagasse is burnt (Fig. 10-30.76\% steam cycle thermal efficiency). When only $30.2 \%$ of the input bagasse is burnt, all the chemical energy rate of the bagasse is used for power generation and for on-site heat recovery, while no heat of combustion is rejected to the environment without being used in the site. It is worth comparing this CHP case with the use of a simple boiler only, which would require only $21 \%$ of the input bagasse to cover the whole process hot utility requirement.

\subsection{Bagasse gasification and syngas fueled combine cycle}

The second CHP system configuration investigated here is based on an integrated gasification combined cycle. Bagasse is gasified in a fast internally circulated fluidized bed gasifier (FICFB) with steam as oxidizing agent. Syngas is used to fuel a gas turbine, and its exhaust flue gases with some extra hot streams from the gasification section (mainly hot gas cleaning) are used to generate the steam in a bottoming steam cycle, which in turn produces power and provides the heat (by means of steam extraction) for the various sugar-cane conversion subprocesses. The steam cycle structure considered for this problem is the same of that in Section 5.1. The structure and all the operating parameters of the gasification, gas cleaning and gas turbine sections are considered fixed, while the steam cycle parameters are optimized together with the multieffect evaporator structural and operating parameters following the objective of maximum total site net power production.

Air drying, gasification, gas cleaning and gas turbine are modeled in details in the BelSim VALI environment according to the data and the modeling approach found in a recent work [35]. The bagasse is 


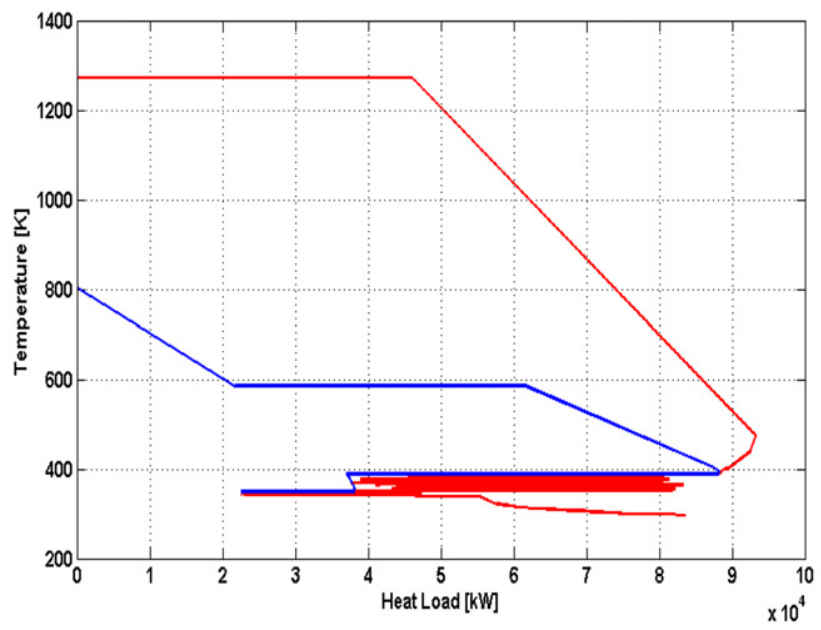

Case 1 results - CHP system 1

(30.2\% bagasse combustion)

Rankine cycle net power $=$

$22562 \mathrm{~kW}$

HP turbine section power $=$

$21593 \mathrm{~kW}$

LP turbine section power $=$

$1281 \mathrm{~kW}$

Process power requirement $=15165 \mathrm{~kW}$

Total site net power $=$

$7397 \mathrm{~kW}$

Cold utility requirement $=$

$\left(14.79 \mathrm{kWh} / \mathrm{t}_{\text {cane }}\right)$

Bagasse input power $=\quad 89830 \mathrm{~kW}$

Total site net thermal efficiency $=8.23 \%$

Fig. 14. Case 1: integrated grand composite curve with CHP system 1 (combustion of $30.2 \%$ input bagasse only).

first dried (from $50 \%$ to $25 \%$ humidity by mass), then is gasified at high temperature $\left(850{ }^{\circ} \mathrm{C}\right)$ in presence of steam $(0.4$ steam to biomass ratio). Bagasse gasification is modeled as a black-box.

The thermodynamic equilibrium of three reactions $\left(\mathrm{C}(\mathrm{s})+2 \mathrm{H}_{2}\right.$ $\leftrightarrow \mathrm{CH}_{4}$ methanation; $\mathrm{C}(\mathrm{s})+\mathrm{CO}_{2} \leftrightarrow 2 \mathrm{CO}$ Boudouard; $\mathrm{CO}+\mathrm{H}_{2} \mathrm{O} \leftrightarrow$ $\mathrm{CO}_{2}+\mathrm{H}_{2}$ water-gas shift) was modeled by specifying a temperature departure from the gasifier operating temperature for each reaction. The typical composition of the FICFB gasifier, reported in [36], was obtained in [35] by adjusting the temperature departures of the three reactions. In addition, the conversion of bagasse into some other heavy compounds (TAR) is considered. Four TAR compounds are specified at the gasifier outlet in order to fairly represent major species at a typical TAR mixture composition in bagasse derived produced gas: Toluene (65\% TAR), Naphthalene (20\% TAR), Phenol (10\% TAR), Pyrene (5\% TAR). In agreement with the data found in [37] a total TAR yield of $5 \mathrm{~g} / \mathrm{Nm}^{3}$ is imposed for the fluidized bed gasifier. Steam to biomass ratio is fixed at 0.2. The gasifier operating temperature is set at $850{ }^{\circ} \mathrm{C}$ and steam temperature at gasifier inlet is set at $400^{\circ} \mathrm{C}$. Char is burnt with a fraction of the produced gas ( $7 \%$ of the total) in order to provide heat to the gasification process by heating the circulating bed material according to the FICFB gasifier design concept. According to the values of the aforementioned parameters, a cold gas efficiency (before gas processing) of 0.86 is obtained. The produced gas at gasifier outlet is a mixture of the following species: $\mathrm{N}_{2}(1.48 \%$ by mass), $\mathrm{CO}_{2}$ (39.17), $\mathrm{CO}$ (3.97), $\mathrm{H}_{2} \mathrm{O}$ (38.16), $\mathrm{CH}_{4}$ (11.64), $\mathrm{H}_{2}$ (0.88), Ethane (4.16), Toluene (0.35), Naphthalene (0.10), Phenol (0.05), Pyrene (0.03).

Hot gas cleaning is used to purify the syngas before the gas turbine. Since the TAR load in the produced gas is fairly low and the gas at the gasifier outlet is used to fuel a gas turbine, the gas cleaning devices considered here are only a cyclone and a candle filter. The major part of particles in the produced gas are considered to be removed through the cyclone, then the gas is cooled down to $500{ }^{\circ} \mathrm{C}$ and is sent to the ceramic filter in which alkali based TAR condensate in a particle form and are mechanically removed.

Since the gas turbine operate with syngas combustion at relative high pressure, the syngas has to be pressurized to be injected in the gas turbine burners and, therefore, pressurized gasification and gas cleaning is adopted here. Such advanced gasification and gas cleaning technologies allow to reach a better performance than the majority of existing BIGCC plants, in which atmospheric gasification and cold gas cleaning are usually employed because of technical and economical reasons. According to some studies reported in the literature [38,39], the pressure of the fluidized bed gasifier for a BIGCC system is set here at 20 bar as a reasonable value. This variable could have been included in the decision variable set of the optimization problem to search for the best thermal coupling between the topping gas turbine cycle and the bottoming steam cycle. However, a preliminary analysis of the heat integration showed that both other streams of the gasification section are hot enough to deliver heat for steam superheating, and turbine exhaust gas temperature $\left(547^{\circ} \mathrm{C}\right)$ is still $20^{\circ} \mathrm{C}$ hotter than the superheated steam maximum temperature, which is set to $527^{\circ} \mathrm{C}$ as in Section 5.1.

A $2 \%$ heat loss from the gasifier and a $4 \%$ heat loss from the cleaning chain were considered. The auxiliary devices of the drying and gasification sections were assumed to require $3 \mathrm{MW}$ of electric power.

In summary, $38.9 \mathrm{~kg} / \mathrm{s}$ of input bagasse are converted in $30.7 \mathrm{~kg} / \mathrm{s}$ of cleaned syngas with an LHV of $8384 \mathrm{~kJ} / \mathrm{kg}$ entering the gas turbine combustor at $500{ }^{\circ} \mathrm{C}$. A combustion efficiency of 0.98 is considered. Compressor and turbine isentropic efficiencies are set to 0.85 . Turbine inlet temperature is set to $1150{ }^{\circ} \mathrm{C}$, resulting in $327 \mathrm{~kg} / \mathrm{s}$ of exhaust gases at $547{ }^{\circ} \mathrm{C}$ at the gas turbine outlet with the following mass fractions: $8.45 \% \mathrm{CO}_{2}(27.67 \mathrm{~kg} / \mathrm{s}), 7.24 \% \mathrm{H}_{2} \mathrm{O}$, $69.71 \% \mathrm{~N}_{2}, 14.59 \% \mathrm{O}_{2}$.

All the heat streams of the gasification, gas cleaning and gas turbine, which in fact are fixed in terms of temperatures and thermal loads, are included in the overall heat integration problem. In this way, all the possible solutions for heat integration between the streams generated within the BIGCC system and the streams of the sugar-cane conversion process are explored through the optimization. A summary of thermal streams of the gasification, gas cleaning and gas turbine subsystems is shown in Table 4. In order to explore different steam cycle configurations, steam production

Table 4

Thermal streams of the gasification section.

\begin{tabular}{|c|c|c|c|c|c|c|}
\hline \multirow[t]{2}{*}{ Subsystem } & \multicolumn{3}{|c|}{ Hot streams } & \multicolumn{3}{|c|}{ Cold streams } \\
\hline & $\operatorname{Tin}[\mathrm{K}]$ & Tout [K] & $\mathrm{Q}[\mathrm{kW}]$ & $\operatorname{Tin}[K]$ & Tout [K] & $\mathrm{Q}[\mathrm{kW}]$ \\
\hline Air-dryer & 343 & 298 & 39190 & 309 & 473 & -43440 \\
\hline Gasifier & & & & 298 & 486 & -6222 \\
\hline (steam prod.) & & & & 486 & 486 & -14740 \\
\hline & & & & 486 & 673 & -3441 \\
\hline Gas cleaning. & 1123 & 773 & 13080 & & & \\
\hline $\begin{array}{l}\text { Char and gas comb. } \\
\text { (FICFB) flue gases }\end{array}$ & 718 & 443 & 6320 & & & \\
\hline Exhaust gas GT & 821 & 443 & 141130 & & & \\
\hline
\end{tabular}


pressure $p_{\text {high }}$, steam extraction pressure $p_{\text {extr }}$ and steam turbine outlet pressure $p_{\text {out }}$ were optimized. Accordingly the optimization problem is set as follows:

$\max f(\bar{x})$

( $f$ returns the total site net power production)

where $(\bar{x})$ is the vector of the following outer level decision variables:

- $n_{\text {UNIT, }} \Delta b_{i}, \Delta T_{i, i+1}$, i.e. the same set of decision variables considered in the previous optimization problems for the multi-effect evaporator (see Sections 5 and 6.1);

- $p_{\text {high }}$, steam production pressure; $p_{\text {high }} \in[60 ; 120]$ bar;

- $p_{\text {extr, }}$ steam extraction pressure; $p_{\text {extr }} \in[2,20]$ bar;

- $p_{\text {out }}$, steam turbine outlet pressure; $p_{\text {out }} \in[0.1 ; 2]$ bar;

- $\dot{m}_{j}$ : the steam mass flow rates.

As in Section 5.1, the optimal value of the decision variable $p_{\text {out }}$ indicates if a condensing turbine or a back-pressure turbine is more convenient. In this case, contrary to the result obtained in Section 5.1, the back-pressure turbine option maximizes the power generation as shown in Fig. 15, where the integrated grand composite curve of the steam bottoming cycle is shown against the remaining total site thermal streams. The thermal efficiency of the optimal integrated gasification combined cycle configuration is $45.5 \%$ (net total site thermal efficiency is $39.4 \%$ ), with an increase of 15 points with respect to direct bagasse combustion (Fig. 10). It is worth noting that, compared to case of a bagasse fuelled steam boiler, the optimal pressure of steam extraction is now at a temperature level higher than that of the first evaporation effect $\left(p_{\text {extr }}=5.32 \mathrm{bar}\right.$ instead of 1.92 bar). This can be justified by observing the heat pocket created by the composition of the thermal profiles of the airdrier and gas turbine exhaust gases in Fig. 15. In fact, if steam were extracted at the temperature level of the first evaporation effect, the utility pinch point would be at that temperature level and the mass flow rates of the steam cycle would be reduced to fulfill this constraint, so that the heat pocket would not be fully exploited.

\subsection{Other advanced features for increasing total site power generation}

Two more advanced configurations of total site heat and power integration are analyzed in this section in order to explore possible further increases of total site net power generation. The first refers to the option of increasing the number of extractions in the steam bottoming cycle of the BIGCC system, whereas the other refers to the option of modifying the process heat cascade by means of a heat pump operating across the process pinch point.

The idea of increasing the number of extractions from the steam turbine is suggested directly by the optimal integrated grand composite curve obtained in Section 5.2. It is apparent in Fig. 15 that some of the steam at 0.47 bar must be condensed by a cold utility, since the overall heat produced by the CHP system is higher than the total process heat requirement. Thus, it is possible to prolong the expansion of the excess steam to be condensed down to 0.1 bar (the lower bound for turbine discharge pressure considered in the previous cases). In addition, an important exergy loss is due to the significant temperature difference between the steam extracted at 5.32 bar and the temperature level of the first evaporation effect. However, the result of the previous optimization show that this exergy loss is still counterbalanced in terms total site net power generation by the greater steam mass flow rate that can be generated by exploiting the whole heat pocket (in Fig. 15 three temperature levels are at or near to the pinch point condition as water is preheated between 5.32 and 101 bar). The aforementioned exergy loss can be avoided if an additional steam extraction is introduced at the level of the first evaporation effect (1.92 bar). Accordingly, the proposed steam bottoming cycle configuration consists of a condensing turbine with three steam extractions (5.32 bar, 1.92 bar and 0.47 bar) and discharge pressure at 0.1 bar. The steam mass flow rates in this configuration are then optimized while all the other streams of the BIGCC system and the sugar-cane conversion process are left unaltered. The resulting integrated grand composite curve presented in Fig. 16 clearly shows how the thermal streams of the blue curve (steam bottoming cycle) are almost perfectly matched to those of the red curve (bagasse drying, gasification and combustion, sugar-cane conversion process). The increase in power generation is greater than $5 \mathrm{MW}$ and the efficiency of the combined cycle increases well $(+1.8$ points).

The other option for improving total site power generation potential is suggested by the fact that the mass flow rate in the low pressure section of the bottoming cycle is limited by the crystallization heat load (Fig. 15). In fact, the largest quota of the steam mass flow rate extracted for process heating is required at the temperature levels of the first evaporation effect and crystallization. Thus, a possible solution to increase the steam mass flow rate expanded to the cold utility level is to reduce process heat requirement by

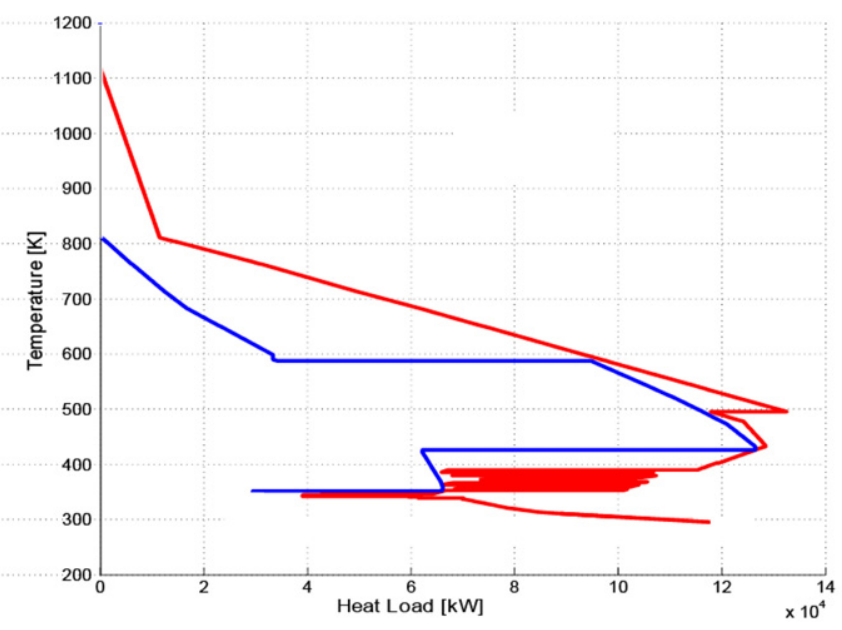

Case 1 results - CHP system 2 (ethanol: $4.19 \mathrm{~kg} / \mathrm{s}$; sugar: $9.21 \mathrm{~kg} / \mathrm{s}$ )

\begin{tabular}{|c|c|}
\hline Gas turbine net power $=$ & se \\
\hline Rankine cycle net power $=$ & $50 \mathrm{~kW}$ \\
\hline Process power requirement. $=$ & $5 \mathrm{~kW}$ \\
\hline Total site net power $=$ & $\begin{array}{l}0 \mathrm{~kW} \\
\left.1 / \mathrm{t}_{\text {cane }}\right)\end{array}$ \\
\hline ility requirement $=$ & \\
\hline Bagasse input power $=$ & $297450 \mathrm{~kW}$ \\
\hline $\begin{array}{l}\text { Total site net thermal efficienc } \\
\text { Steam cycle pressures: }\end{array}$ & $y=39.37 \%$ \\
\hline$p_{\text {high }}$ & $0.7 /$ va \\
\hline $\begin{array}{ll}b_{1}=17.6 \% ; & b_{2}=22.2 \% ; \\
b_{4}=40.0 \% ; & p_{2}=1.34 \mathrm{bar} ; \\
p_{4}=0.71 \mathrm{bar} ; & p_{5}=0.45 \mathrm{bar} ;\end{array}$ & $\begin{array}{l}b_{3}=27.6 \% \\
p_{3}=1.01 \mathrm{bar}\end{array}$ \\
\hline
\end{tabular}

Fig. 15. Case 1: integrated grand composite curve with CHP system 2. 


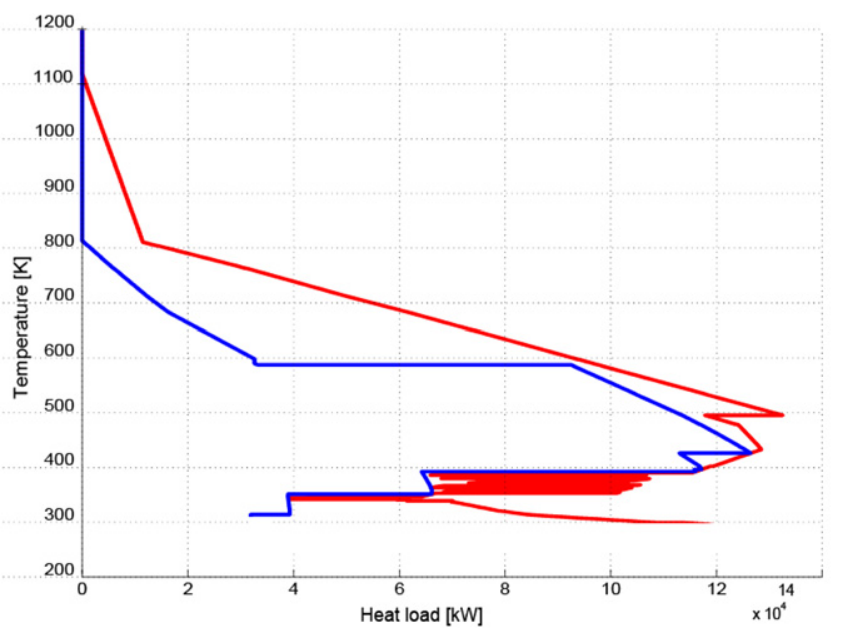

Case 1 results - advanced CHP system

(combined cycle + heat pump across

crystallization temperature level)

Gas turbine net power $=\quad 106644 \mathrm{~kW}$

Rankine cycle net power $=31196 \mathrm{~kW}$

Process power requirement $=15165 \mathrm{~kW}$

Total site net power $=\quad 122675 \mathrm{~kW}$

$\left(245.35 \mathrm{kWh} / \mathrm{t}_{\text {cane }}\right)$

Cold utility requirement $=\quad 87995 \mathrm{~kW}$

Bagasse input power $=\quad 297450 \mathrm{~kW}$

Total site net thermal efficiency $=41.24 \%$

Steam cycle pressures:

$p_{\text {high }}=101$ bar; $p_{\text {extr } 1}=5.32$ bar; $p_{\text {extr } 2}=1.92$ bar

$p_{\text {extr } 3}=0.47$ bar; $p_{\text {out }}=0.1 \mathrm{bar}$;

Fig. 16. Case 1: integrated grand composite curve of a condensing turbine with 3 steam extractions.

means of heat pumps. According to Pinch Analysis rules, these must be placed across the pinch points of the process thermal cascade, and in Figs. 15 and 16 clearly show that the crystallization thermal stream (red curve) activates a utility pinch point with the thermal stream of water preheating at low pressures (blue curve). Since a large quantity of steam is produced by water evaporation at the crystallization pans, the heat pump effect can be simply obtained by vapor recompression. On one hand this increases the power requirement of the process due to the extra power needed for steam compression. On the other hand the crystallization thermal streams would be reduced or even canceled in the process thermal cascade as the result of the local thermal integration, thus allowing a higher steam mass flow rate to be expanded to 0.1 bar. The coefficient of performance (COP) of vapor recompression can be roughly assessed considering the temperature of the steam exiting crystallization pans (around $70{ }^{\circ} \mathrm{C}$ ) and setting the condensation temperature after steam compression to $80^{\circ} \mathrm{C}$, that is $10^{\circ} \mathrm{C}$ hotter than crystallization operating temperature. Under these assumptions the estimated value of the COP is 17 . Accordingly, in order to increase net power generation, the steam mass flow rate undergoing vapor recompression should be counterbalanced at least by an equivalent steam mass flow rate performing a Rankine cycle with $6 \%$ thermal efficiency $(1 / \mathrm{COP}=0.059)$. Indeed, with reference to the case in Fig. 16, the increase in steam power cycle could be obtained by expanded a larger amount of steam to 0.1 bar instead of 0.47 bar (corresponding to the temperature level of crystallization), and as a result the efficiency of the Rankine cycle performed by this portion of steam cycle would increase of about 10 points. Thus, the additional steam to be expanded from 101 to 0.1 bar should be more than $60 \%$ of the steam to be recompressed in order to counterbalance the additional power needed by recompression. Actually, a detailed calculation of steam mass flow rates shows that the additional steam that can be produced and used for increasing net power generation with local vapor recompression at crystallization temperature level is far less than $60 \%$ of the steam to be recompressed, hence vapor recompression is apparently a solution to be dropped for thermodynamic reasons.

\section{Conclusions}

The paper shows the benefits deriving from applying the synthesis/design optimization procedure to a system configuration in which heat exchangers do not exist, being replaced by the only hot and cold thermal streams involved in the internal heat transfer.
This approach is applied to the analysis of a real combined sugar and ethanol production process.

Heat and energy requirements of the process alone are first analyzed showing possible significant improvements with respect to the base case scenario. A one third reduction of the hot utility requirement can be achieved mainly by adjusting the synthesis/ design parameters of the multi-effect evaporator, which indeed is responsible for the largest quota of the heat demand. Moreover, the synthesis optimization of the multi-effect evaporator shows that the same reduction can be achieved by different possible configurations. Additional optimization criteria should therefore be considered for the ultimate choice.

Then, the conceptual design of a CHP system fuelled with bagasse (the main process by-product) and its integration with the production process is presented. Different CHP system configurations are considered, the main constraint for thermal integration being the utility pinch point at the sugar crystallization. In particular, starting from $138.9 \mathrm{~kg} / \mathrm{s}$ of sugar-cane, the present analysis shows that, in addition to the sugar and ethanol production rates $(9.21 \mathrm{~kg} / \mathrm{s}$ and $4.19 \mathrm{~kg} / \mathrm{s}$ respectively in the base case condition), a CHP system fuelled with all the bagasse extracted form the sugarcane can cover the entire process heat requirement and still produce a considerable amount of electrical power that can be sold to the grid ( $76 \mathrm{MW}\left(=153 \mathrm{kWh} / \mathrm{t}_{\text {cane }}\right)$ in the case of traditional combustion and steam cycle power plant, up to $122 \mathrm{MW}$ $\left(=245 \mathrm{kWh} / \mathrm{t}_{\text {cane }}\right)$ in the case of advanced BIGCC power plant).

The presented results are obtained considering pure thermodynamic objective functions, but give potential indications for thermoeconomic improvements. Further studies are needed in this direction to evaluate alternatives (e.g.,[28,29,40]) to the traditional solutions for bagasse recovering presented here, and to explore new techniques for the exploitation of other by-products of juice treatment, fermentation and distillation processes.

\section{References}

[1] Linnhoff B, Townsend DW, Boland D, Hewitt GF, Thomas BEA, Guy AR, et al. A User guide on process integration for the efficient use of energy. Rugby, UK: Institution of Chemical Engineers; 1994.

[2] Bejan A, Tsatsaronis G, Moran M. Thermal design \& optimization. New York: John Wiley \& Sons Inc; 1996.

[3] Sciubba E, Melli R. "Toward automatic process simulator2: Part I - Modular numerical procedures, Part II - An expert system for process synthesis. Journal of Engineering for Gas Turbines and Power 1998;120:1-16.

[4] Maréchal F, Kalitvenzeff B. Effect modelling and optimization: a new methodology for combined energy and environment synthesis of industrial processes. Applied Thermal Engineering 1997;17:981-92. 
[5] Lazzaretto A, Segato F. Thermodynamic optimization of the HAT cycle plant structure. Part I: optimization of the basic plant configuration". Part II: structure of the heat exchanger networks". Journal of Engineering for Gas Turbines and Power 2001;123:1-16.

[6] Lazzaretto A, Toffolo A. A method to separate the problem of heat transfer interactions in the synthesis of thermal systems. Energy 2008;33(2):163-70.

[7] Guallar PJ. Analisis exergetico e integracion termica de processos en la industria azucarera. PhD thesis, University of Zaragoza; 1987.

[8] Christodoulou P. The pinch technology and the energy reduction in the beet sugar process. Zuckerind 1992;117(3):169-75.

[9] Ram JR, Banerjee R. Energy and cogeneration targeting for a sugar factory. Applied Thermal Engineering 2003;23:1567-75.

[10] Urbaniec $\mathrm{K}$. The evolution of evaporator stations in the beet-sugar industry. Journal of Food Engineering 2004;61(4):505-8.

[11] Higa M, Freitas AJ, Bannwart AC, Zemp RJ. Thermal integration of multiple effect evaporator in sugar plant. Applied Thermal Engineering 2009;29(2-3):515-22.

[12] Krajnc D, Glavič P. Assessment of different strategies for the co-production of bioethanol and beet sugar. Chemical Engineering Research and Design 2009;87(9):1217-31.

[13] Ensinas AV, Nebra SA, Lozano MA, Serra LM. Analysis of process steam demand reduction and electricity generation in sugar and ethanol production from sugarcane. Energy Conversion and Management 2007; 48:2978-87.

[14] Ensinas AV. Integraçao termica and otimizaçao termoeconomica aplicadas ao processo industrial de produçao de aucar e etanol a partir da cana-de-aucar. PhD thesis, Mechanical Engineering Faculty, State University of Campinas: 2008.

[15] Hugot E. Handbook of sugar cane engineering. 3rd ed. New York: Elsevier; 1986.

[16] Rein P. Cane sugar engineering. Berlin: Verlag Dr. Albert Bartens KG; 2007.

[17] Pollach G, Schiweck H, Clarke M. Sugar. In: Ullmann's Encylopedia of Industrial Chemistry. Wiley-VCH Verlag GmbH \& Co KGaA; 2007.

[18] Farkas A, Sahm H, Bringer-Meyer S, Goebel O, Mayer D, Kosaric N, et al. Ethanol. In: Ullmann's Encylopedia of Industrial Chemistry. Wiley-VCH Verlag GmbH \& Co, KGaA; 2002.

[19] Nebra SA, Fernandez-Parra MI, 2005. The exergy of sucrose-water solutions: proposal of a calculation method. In: Proceeding of ECOS2005; 2005: p. 385-392.

[20] Ensinas AV, Modesto M, Nebra SA, Serra LM. Reduction of irreversibility generation in sugar and ethanol production from sugarcane. Energy 2009;34(5):680-8.

[21] Peacock S. Predicting physical properties of factory juices and syrups. International Sugar Journal 1995;97:571-7.

[22] Périn-Levasseur Z, Palese V, Maréchal F. Energy integration study of a multieffect evaporator. In: Proceedings of the 11th Conference on Process Integration, Modelling and Optimisation for Energy Saving and Pollution Reduction; 2008.
[23] Gassner M, Maréchal F. Methodology for the optimal thermo-economic, multi-objective design of thermochemical fuel production from biomass. Computers \& Chemical Engineering 2009;33:769-81.

[24] Leyland GB. Multi-objective optimisation applied to industrial energy problems. Ph.D. thesis, Ecole polytechnique fédérale de Lausanne; 2002.

[25] Pellegrini LF, de Oliveira Jr S. Energy analysis of sugar cane bagasse gasification. Energy 2007;32:314-27.

[26] Restuti D, Michaelowa A. The economic potential of bagasse cogeneration as CDM projects in Indonesia. Energy Policy 2007;35:3952-66.

[27] Serra LM, Lozano MA, Ramos J, Ensinas AV, Nebra SA. Polygeneration and efficient use of natural resources. Energy 2009;34(5):575-86.

[28] Cardona AC, Sánchez JO. Fuel ethanol production: process design trends and integration opportunities. Biosource Technology 2007;98:2415-57.

[29] Kaar WE, Gutierrez CV, Kinoshita CM. Steam explosion of sugarcane bagasse as a pretreatment for conversion to ethanol. Biomass and Bioenergy 1998; $14: 227-87$

[30] Luo L, van der Voet E, Huppes G. Life cycle assessment and life cycle costing of bioethanol from sugarcane in Brazil. Renewable and Sustainable Energy Reviews 2009;13(6-7):1613-9.

[31] Zhang S, Maréchal F, Gassner M, Périn-Levasseur Z, Qi W, Ren Z, et al. Process modeling and integration of fuel ethanol production from lignocellulosic biomass based on double acid hydrolysis. Energy Fuels 2009;23:1759-65.

[32] Maréchal F, Kalitvenzeff B. Process integration: selection of the optimal utility system". Computers \& Chemical Engineering Supplement 1998;22:s149-56.

[33] Maréchal F, Kalitvenzeff B. Targeting the optimal integration of steam networks: Mathematical tools and methodology. Computers \& Chemical Engineering 1999;23:s133-6.

[34] Friedli A, Padouvas E, Rotter H, Varmuza K. Prediction of heating values of biomass fuel from elemental composition. Analytica Chimica Acta 2005;544:191-8.

[35] Gassner M, Maréchal F. Thermo-economic process model for thermochemica production of Synthetic Natural Gas (SNG) from lignocellulosic biomass. Biomass and Bioenergy 2009;33(11):1587-604.

[36] Hofbauer H, Rauch R, Loeffler G, Kaiser S, Fercher E, Tremmel H. Six years experience with the FICFB gasification process. In: 12th European Conference and Technology Exhibition on Biomass for Energy, Industry and Climate Protection; 2002.

[37] Han J, Kim H. The reduction and control technology of tar during biomass gasification/pyrolis: an overview. Renewable and Sustainable Energy Reviews 2006;12:397-416.

[38] Craig RK, Mann KM. Cost and performances analysis of a biomass-based integrated gasification combined cycle (BIGCC) power systems. NREL/TP430-21657; 1996

[39] Shaub G. Gas Production: Chapter 4-Gas production from coal, wood, and other solid feedstocks. In: Ullmann's Encylopedia of industrial Chemistry. Wiley-VCH Verlag GmbH \& Co KGaA; 2007.

[40] Contreras AM, Rosa E, Perez M, Van Langenhove H, Dewulf J. Comparative Life Cycle Assessment of four alternatives for using by-products of cane sugar production. Journal of Cleaner Production 2009;17:772-9. 